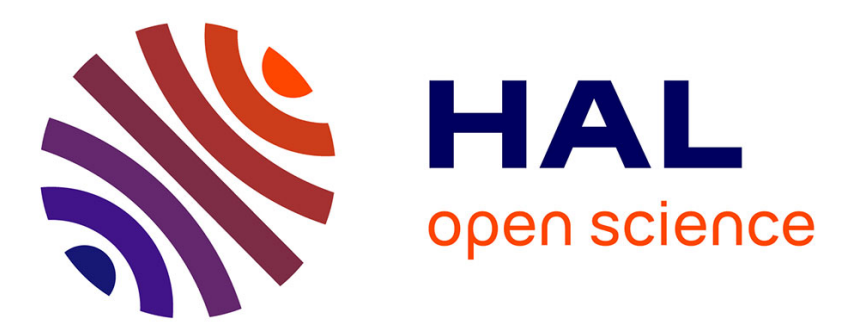

\title{
Nature of $\mathrm{Cp}^{*} \mathrm{MoO} 2+$ in Water and Intramolecular Proton-Transfer Mechanism by Stopped-Flow Kinetics and Density Functional Theory Calculations
}

Joo-Eun Jee, Aleix Comas-Vives, Chiara Dinoi, Gregori Ujaque, Rudi van

Eldik, Agusti Lledos, Rinaldo Poli

\section{To cite this version:}

Joo-Eun Jee, Aleix Comas-Vives, Chiara Dinoi, Gregori Ujaque, Rudi van Eldik, et al.. Nature of $\mathrm{Cp}^{*} \mathrm{MoO} 2+$ in Water and Intramolecular Proton-Transfer Mechanism by Stopped-Flow Kinetics and Density Functional Theory Calculations. Inorganic Chemistry, 2007, 46 (10), pp.4103-4113. 10.1021/ic062409g . hal-03194455

\section{HAL Id: hal-03194455 \\ https://hal.science/hal-03194455}

Submitted on 9 Apr 2021

HAL is a multi-disciplinary open access archive for the deposit and dissemination of scientific research documents, whether they are published or not. The documents may come from teaching and research institutions in France or abroad, or from public or private research centers.
L'archive ouverte pluridisciplinaire HAL, est destinée au dépôt et à la diffusion de documents scientifiques de niveau recherche, publiés ou non, émanant des établissements d'enseignement et de recherche français ou étrangers, des laboratoires publics ou privés. 


\section{Nature of $\mathrm{Cp}^{*} \mathrm{MoO}_{2}{ }^{+}$in water and intramolecular proton-transfer mechanism by stopped-flow kinetics and Density Functional Theory calculations}

Joo-Eun Jee, ${ }^{\mathrm{a}}$ Aleix Comas-Vives, ${ }^{\mathrm{b}}$ Chiara Dinoi, ${ }^{\mathrm{c}}$ Gregori Ujaque, ${ }^{\mathrm{b}}$ Rudi van Eldik, ${ }^{* \mathrm{a}}$ Agustí Lledós, ${ }^{* \mathrm{~b}}$ and Rinaldo Poli*c

anstitute for Inorganic Chemistry, University of Erlangen-Nürnberg, Egerlandstr. 1, 91058 Erlangen, Germany

${ }^{\mathrm{b}}$ Unitat de Química Física, Departament de Química, Edifici Cn, Universitat Autònoma de Barcelona, 08193 Bellaterra, Catalonia, Spain

${ }^{\mathrm{C}}$ Laboratoire de Chimie de Coordination, UPR CNRS 8241 liée par convention à l'Université Paul

Sabatier et à l'Institut National Polytechnique de Toulouse, 205 Route de Narbonne, 31077 Toulouse

Cedex, France

Proofs to :

Rinaldo Poli

Tel +33-561333173

Fax +33-561553003

E-mail poli@1cc-toulouse.fr 


\begin{abstract}
A stopped-flow study of the $\mathrm{Cp}^{*} \mathrm{MoO}_{3}{ }^{-}$protonation at low $\mathrm{pH}$ (down to zero) in a mixed $\mathrm{H}_{2} \mathrm{O}-\mathrm{MeOH}$ (80:20) solvent at $25^{\circ} \mathrm{C}$ allows the simultaneous determination of the first acid dissociation constant of the oxo dihydroxo complex, $\left[\mathrm{Cp} * \mathrm{MoO}(\mathrm{OH})_{2}\right]^{+}\left(\mathrm{p} K_{\mathrm{a} 1}=-0.56\right)$, and the rate constant of its isomerization to the more stable dioxo aqua complex $\left[\mathrm{Cp}^{*} \mathrm{MoO}_{2}\left(\mathrm{H}_{2} \mathrm{O}\right)\right]^{+}\left(k_{-2}=28 \mathrm{~s}^{-1}\right)$. Variable temperature $\left(5-25^{\circ} \mathrm{C}\right)$ and variable pressure $(10-130 \mathrm{MPa})$ kinetics studies have yielded the activation parameters for the combined protonation/isomerization process $\left(k_{-2} / K_{\mathrm{a} 1}\right)$ from $\mathrm{Cp}^{*} \mathrm{MoO}_{2}(\mathrm{OH})$ to $\left[\mathrm{Cp}^{*} \mathrm{MoO}_{2}\left(\mathrm{H}_{2} \mathrm{O}\right)\right]^{+}$, viz. $\Delta H^{*}=5.1 \pm$ $0.1 \mathrm{kcal} \mathrm{mol}^{-1}, \Delta S^{\ddagger}=-37 \pm 1 \mathrm{cal} \mathrm{mol}^{-1} \mathrm{~K}^{-1}$ and $\Delta V^{\ddagger}=-9.1 \pm 0.2 \mathrm{~cm}^{3} \mathrm{~mol}^{-1}$. Computational analysis of the two isomers, as well as the $\left[\mathrm{Cp}^{*} \mathrm{MoO}_{2}\right]^{+}$complex resulting from the dissociation of water, reveal a crucial solvent effect on both the isomerization and the water dissociation energetics. Introducing a solvent model by CPCM and especially by explicitly including up to three water molecules in the calculations led to the stabilization of the dioxo aqua species relative to the oxo dihydroxo isomer, and to the substantial decrease of the energy cost for the water dissociation process. The presence of a water dissociation equilibrium is invoked to account for the unusually low effective acidity $\left(\mathrm{p} K_{\mathrm{a} 1}{ }^{\prime}=4.19\right)$ of the $\left[\mathrm{Cp}^{*} \mathrm{MoO}_{2}\left(\mathrm{H}_{2} \mathrm{O}\right)\right]^{+}$ion. In addition, the computational study reveals the positive role of external water molecules as simultaneous proton donors and acceptors, having the effect of dramatically lowering the isomerization energy barrier.
\end{abstract}




\section{Introduction}

The precise structure of aqua complexes and ions in water solution is rarely known. For instance, molybdic acid $\left(\mathrm{H}_{2} \mathrm{MoO}_{4}\right)$ is commonly represented as $\mathrm{Mo}(\mathrm{OH})_{6}, \mathrm{MoO}_{2}(\mathrm{OH})_{2}\left(\mathrm{H}_{2} \mathrm{O}\right)_{2}$ and $\mathrm{MoO}_{3}\left(\mathrm{H}_{2} \mathrm{O}\right)_{3}$, ${ }^{1-6}$ while its first protonation product has been described as $\mathrm{Mo}(\mathrm{OH})_{5}\left(\mathrm{H}_{2} \mathrm{O}\right)^{+}$or $\mathrm{MoO}_{2}(\mathrm{OH})\left(\mathrm{H}_{2} \mathrm{O}\right)_{3}{ }^{+1,}, 4,5$ although the isomeric formulation $\mathrm{MoO}(\mathrm{OH})_{3}\left(\mathrm{H}_{2} \mathrm{O}\right)_{2}{ }^{+}$could also be envisaged. To the best of our knowledge, the factors regulating the relative energy of a transition metal dihydroxo complex and its isomeric aqua-oxo form (Scheme 1) are not well understood. In terms of the rate and mechanism of water exchange reactions, the correct assignment of such species is of utmost importance since it is well known that water exchange reactions follow the reactivity order $\mathrm{M}-\mathrm{OH}_{2}>\mathrm{M}-\mathrm{OH}>\mathrm{M}=\mathrm{O} .^{7}$
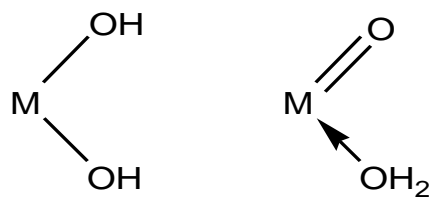

\section{Scheme 1}

In the organometallic area, the complex $\mathrm{Cp}^{*}{ }_{2} \mathrm{Zr}(\mathrm{OH})_{2}$ is a stable compound, ${ }^{8}$ whereas $\mathrm{Cp}^{*}{ }_{2} \mathrm{ZrO}$ is a reactive intermediate. ${ }^{9}$ On the other hand, $\mathrm{Cp}^{*}{ }_{2} \mathrm{WO}$ and $\mathrm{Cp}_{2}{ }_{2} \mathrm{Ta}(\mathrm{O}) \mathrm{H}$ are stable compounds that exchange water through $\mathrm{Cp}^{*}{ }_{2} \mathrm{~W}(\mathrm{OH})_{2}$ and $\mathrm{Cp}^{*}{ }_{2} \mathrm{Ta}(\mathrm{OH})_{2} \mathrm{H}$ intermediates. ${ }^{10}$ Finally, the closely related oxo and dihydroxo complexes $\left[\mathrm{CpMoO}\left(\mathrm{PMe}_{3}\right)_{2}\right]^{+}$and $\left[\left(\eta^{5}-\mathrm{C}_{5} \mathrm{Et}_{5}\right) \mathrm{Mo}(\mathrm{OH})_{2}(\mathrm{dppe})\right]^{+}$have been isolated and structurally characterized. ${ }^{11,12}$ In these systems, $\mathrm{Cp}, \mathrm{Cp}{ }^{*}$ and related chelates are expected to have a drastic influence of the rate and mechanism of the water exchange process on the basis of data reported in the literature for water exchange on $\left[\mathrm{Cp} * \mathrm{Rh}\left(\mathrm{H}_{2} \mathrm{O}\right)_{3}\right]^{2+}$ and $\left[\mathrm{Cp} * \operatorname{Ir}\left(\mathrm{H}_{2} \mathrm{O}\right)_{3}\right]^{2+}$, which is 14 orders of magnitude faster than for the corresponding hexaaqua complexes and proceeds according to a more dissociative substitution mode..$^{13,14}$ 
Some of us have initiated an investigation of the aqueous chemistry of high oxidation state organometallic compounds, focusing initially on $\mathrm{Cp} *$ Mo derivatives in a variety of oxidation states (VI, V, IV, and mixed-valence clusters). ${ }^{15}$ High oxidation state oxomolybdenum compounds are employed in a variety of catalytic reactions, such as olefin epoxidation, the selective oxidation of alcohols to aldehydes, the dehydrogenation and isomerization of alkenes, and even reductive processes such as the hydrosilylation of carbonyl compounds. ${ }^{16}$ Organometallic versions of these systems have shown high activities, notably in olefin epoxidation. ${ }^{17-20}$ It would therefore be of interest to adapt these catalytic processes to an aqueous environment. To this end, knowledge of the nature of the $\mathrm{Cp}^{*} \mathrm{Mo}^{\mathrm{VI}}$ aqua ion under different $\mathrm{pH}$ conditions is very useful.

A previous investigation of the aqueous speciation of $\mathrm{Cp}^{*} \mathrm{Mo}^{\mathrm{VI}}$ has given the results summarized in Figure $1 .{ }^{21}$ In particular, the rate of conversion of compound $\mathrm{Cp}^{*} \mathrm{MoO}_{2}(\mathrm{OH})$ (generated quantitatively by the rapid protonation of $\mathrm{Cp}^{*} \mathrm{MoO}_{3}{ }^{-}$at $\mathrm{pH} \leq 2$ ) to the final cationic product was found to be first order in $\left[\mathrm{H}^{+}\right]$. The interpretation of this result leaves two possibilities as detailed in Scheme 2, both involving a proton addition pre-equilibrium to yield an intermediate cationic dihydroxo complex. The first possibility (path $a$ ) involves a rapid equilibrium rearrangement to an aqua-oxo isomer, followed by rate-determining loss of a water ligand, whereas the second one (path $b$ ) involves the intramolecular isomerization process as a rate-determining step. The $\left[\mathrm{Cp}^{*} \mathrm{MoO}(\mathrm{OH})_{2}\right]^{+}$ion is likely a strong acid in water $\left(\mathrm{p} K_{\mathrm{a} 1}<0\right)$, since most multiprotic inorganic oxo acids (e.g. $\mathrm{H}_{2} \mathrm{CO}_{3}, \mathrm{H}_{2} \mathrm{SO}_{3}, \mathrm{H}_{3} \mathrm{PO}_{4}, \ldots$ ) are characterized by a $\Delta \mathrm{p} K_{\mathrm{a}}$ of ca. 4-5 and the $\mathrm{p} K_{\mathrm{a} 2}$ (acid dissociation of $\mathrm{Cp}^{*} \mathrm{MoO}_{2}(\mathrm{OH})$ ) is 3.65. Thus, the aquation state of the final cationic product is uncertain, $\left[\mathrm{Cp}^{*} \mathrm{MoO}_{2}\left(\mathrm{H}_{2} \mathrm{O}\right)_{n}\right]^{+}$with either $\mathrm{n}=0$ or 1 . The two possibilities cannot be distinguished on the basis of the kinetics experiment, nor by use of ${ }^{1} \mathrm{H}$ NMR spectroscopy because only the large solvent resonance was observed under all $\mathrm{pH}$ conditions, providing only negative evidence for water coordination (the resonance of the coordinated water molecule could either be overshadowed by the 
much stronger solvent resonance, of the ligand exchange is in the fast regime leading to a single averaged resonance). IR spectroscopy is also useless for such dilute solutions in a strongly absorbing medium.

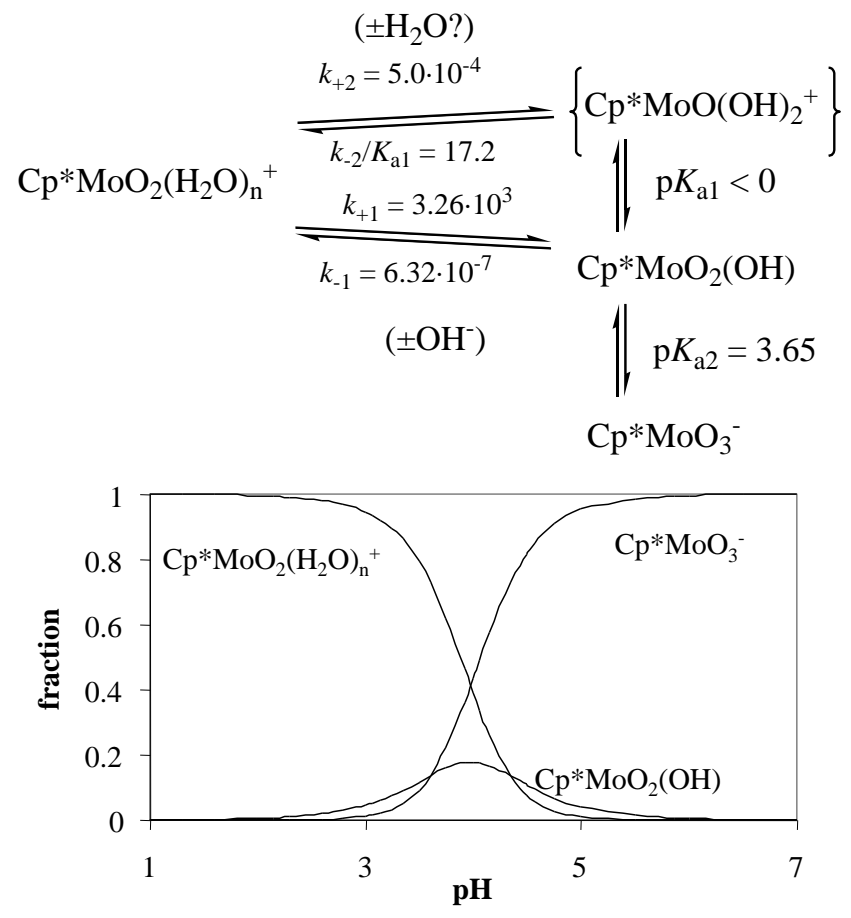

Figure 1. Thermodynamic and kinetic parameters related to the $\mathrm{Cp}^{*} \mathrm{Mo}^{\mathrm{VI}}$ system in a $\mathrm{H}_{2} \mathrm{O}-\mathrm{MeOH}$ (80:20) solution. ${ }^{21}$

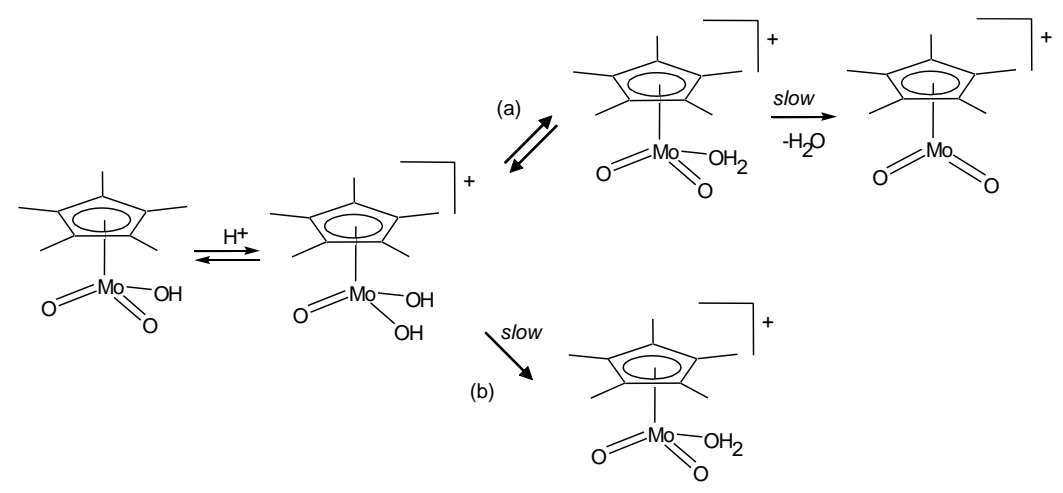

\section{Scheme 2}


Subsequent attempts to crystallize a salt of the $\left[\mathrm{Cp}^{*} \mathrm{MoO}_{2}\left(\mathrm{H}_{2} \mathrm{O}\right)_{\mathrm{n}}\right]^{+}$ion and to determine its aquation state by X-ray crystallography have not been successful, always yielding instead the neutral dinuclear compound $\mathrm{Cp}_{2}{ }_{2} \mathrm{Mo}_{2} \mathrm{O}_{5}{ }^{22}$ In fact, the low solubility product of this compound drives its precipitation by combination with the thermodynamically unfavorable (at low $\mathrm{pH}$, see Figure 1) anionic hydrolysis product, $\mathrm{Cp}^{*} \mathrm{MoO}_{3}$. Another point that has remained unexplained from the previous study ${ }^{21}$ concerns the greater thermodynamic stability of the dioxo cation, $\mathrm{Cp}^{*} \mathrm{MoO}_{2}{ }^{+}$(or its water adduct) relative to the oxo dihydroxo isomer, $\mathrm{Cp} * \mathrm{MoO}(\mathrm{OH})_{2}{ }^{+}$.

In this contribution, we present a more detailed stopped-flow kinetics investigation of the generation of the $\left[\mathrm{Cp}^{*} \mathrm{MoO}_{2}\left(\mathrm{H}_{2} \mathrm{O}\right)_{\mathrm{n}}\right]^{+}$ion in the low $\mathrm{pH}$ regime, including variable temperature and variable pressure experiments, as well as a DFT computational study aimed at establishing $(i)$ the aquation state of this ion and (ii) the mechanism of the slow process which leads to its generation. The results of this theoretical investigation are potentially of more general interest, as they illustrate the effect of the medium on the relative stability of oxo and dihydroxo transition metal species.

\section{Results and Discussion}

\section{(a) Aquation state of $\left[\mathrm{Cp}^{*} \mathrm{MoO}_{2}\left(\mathrm{H}_{2} \mathrm{O}\right)_{\mathrm{n}}\right]^{+}$}

The reaction shown in Equation 1 was studied computationally by DFT methods on the full systems (i.e. no ligand simplification was adopted). Both complexes were optimized in the gas phase. These two minima are shown in Figure 2. The unsolvated species give rise to a bent geometry, with the Mo-Cp* ring centroid axis forming an angle of $136.9^{\circ}$ from the $\mathrm{MoO}_{2}$ plane, which is only slightly smaller than the same angle in the water adduct $\left(141.9^{\circ}\right)$. Relative to the ideal planar structure (optimized independently under constrained $\mathrm{C}_{\mathrm{s}}$ symmetry), this configuration is more stable by only $2.9 \mathrm{kcal} \mathrm{mol}^{-1}$. 


$$
\left[\mathrm{Cp} * \mathrm{MoO}_{2}\right]^{+}+\mathrm{H}_{2} \mathrm{O} \rightleftarrows\left[\mathrm{Cp}^{*} \mathrm{MoO}_{2}\left(\mathrm{H}_{2} \mathrm{O}\right)\right]^{+}(\mathbf{2 a})
$$

\section{Equation 1}
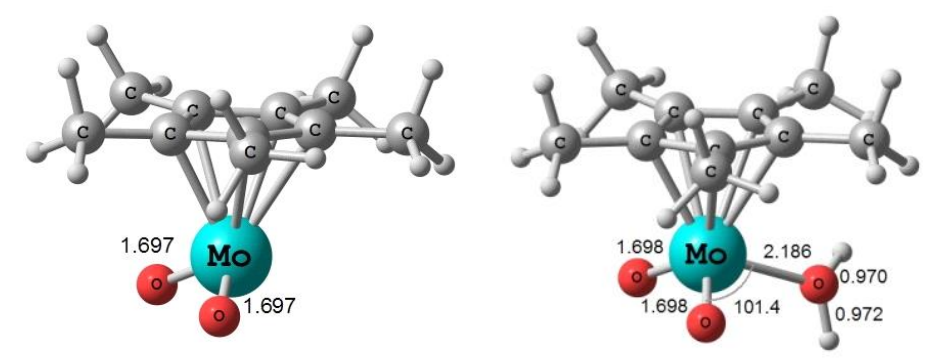

Figure 2. Optimized structures of the $\left[\mathrm{Cp}^{*} \mathrm{MoO}_{2}\right]^{+}$and $\left[\mathrm{Cp}^{*} \mathrm{MoO}_{2}\left(\mathrm{H}_{2} \mathrm{O}\right)\right]^{+}(\mathbf{2 a})$ complexes.

The electronic structure of two-legged piano stool complexes has been analyzed before, ${ }^{23-25}$ including the effect of the coordination environment ${ }^{26,27}$ and spin state 28,29 on the relative stability of planar and bent geometries. All previous studies, however, are restricted to electronically unsaturated (16electron) $d^{6}$ systems, typically containing $\pi$-acidic (e.g. CO), neutral (e.g. H), or weakly donating (e.g. $\mathrm{Cl}$ ) ligands. On the other hand, complex $\left[\mathrm{Cp}^{*} \mathrm{MoO}_{2}\right]^{+}$features two strong double-sided $\pi$-donors on a $d^{0}$ metal center. Since the $\mathrm{Cp}^{*-}$ ligand is electronically isolobal with the $\mathrm{O}^{2-}$ ligand (both are potentially 6electron, $\sigma+2 \pi$ donors), the compound can also be considered as isolobally related to $\mathrm{MoO}_{3}$, which is a $d^{0}$ $\mathrm{MX}_{3}$ systems with strong double-sided $\pi$ donor ligands. The geometric preference for $d^{0} \mathrm{MX}_{3}$ systems has been recently analyzed by Eisenstein et $a l .{ }^{30}$ for $\mathrm{M}=$ Group 3, Group 4 and lanthanide elements, and $\mathrm{X}=$ alkyl, halide and amido groups. It was found that the pyramidal structure is always preferred because of the d orbital participation in M-X $\sigma$ bonding, whereas the ionic component should favor the planar structure. The contribution from $\pi$ donation provides a driving force towards flattening the structure. Therefore, it seems that the Mo-Cp* and Mo-O $\sigma$ interactions dominates the geometric preference for the $\left[\mathrm{Cp}^{*} \mathrm{MoO}_{2}\right]^{+}$ion. We have also calculated the isolobal $\mathrm{MoO}_{3}$ system and found that the pyramidal 
structure $\left(\mathrm{O}-\mathrm{Mo}-\mathrm{O}=109.7^{\circ}\right)$ is again favored, in this case by $9.5 \mathrm{kcal} \mathrm{mol}^{-1}$ with respect to the $\mathrm{D}_{3 \mathrm{~h}}$ structure. The Mo-ligand interactions nevertheless have a significant contribution from ionicity. This is suggested by the values of the Mulliken charges, for instance the charges in the $\left[\mathrm{Cp} * \mathrm{MoO}_{2}\right]^{+}$ion are +1.38 for Mo and -0.52 (average) for the two $\mathrm{O}$ atoms, whereas in the $\mathrm{MoO}_{3}$ molecule they are +1.88 and -0.63 , respectively, showing that the metal is electron-richer in $\left[\mathrm{Cp} * \mathrm{MoO}_{2}\right]^{+}$than in $\mathrm{MoO}_{3}$.

As expected, the addition of a water molecule results in an energetic stabilization of the $\left[\mathrm{Cp} * \mathrm{MoO}_{2}\right]^{+}$complex, corresponding to a potential energy gain of $39.7 \mathrm{kcal} / \mathrm{mol}$ in the gas phase. In addition to providing additional covalent bonding stabilization, this process is also favorable from an electrostatic point of view, since a positively charged Mo atom (Mulliken charge 1.37) is directly linked to the oxygen atom of a water molecule which has a marked anionic character (Mulliken charge -0.71). Although this addition process is entropically disfavored, the free energy difference of the reaction is still exergonic by $28.1 \mathrm{kcal} / \mathrm{mol}$. The inclusion of solvent effects by means of the CPCM method changes significantly the results. The energetic difference remains in favor of the water adduct but the gain is reduced to $10.1 \mathrm{kcal} / \mathrm{mol}$. Having the $\mathrm{Cp}^{*} \mathrm{MoO}_{2}{ }^{+}$and the $\mathrm{H}_{2} \mathrm{O}$ molecules separated in the gas phase is a very energy costing process because a strong cation-dipole interaction is broken. Adding solvent effects stabilize the separated reactants by interacting with the dielectric continuum of the polar medium, leading to a considerable decrease in the energy difference between the isolated species and the aqua complex. The conclusion of this investigation is to establish the nature of the acidic form of $\mathrm{Cp}^{*} \mathrm{Mo}^{\mathrm{VI}}$ in water as the aqua complex $\left[\mathrm{Cp}^{*} \mathrm{MoO}_{2}\left(\mathrm{H}_{2} \mathrm{O}\right)\right]^{+}$, although the dissociation of the water ligand to afford the $\left[\mathrm{Cp} * \mathrm{MoO}_{2}\right]^{+}$intermediate may be a facile process. As mentioned in the Introduction, from a kinetics point of view, the $\mathrm{Cp} *$ ligand is known to exert a strong trans effect on ligand dissociation processes. The introduction of the $\mathrm{Cp}^{*}$ ligand on the very inert hexa-aqua complexes of $\operatorname{Ir}(\mathrm{III})$ and $\mathrm{Rh}(\mathrm{III})$, i.e. on going from the $\left[\mathrm{M}\left(\mathrm{H}_{2} \mathrm{O}\right)_{6}\right]^{3+}$ to the $\left[\mathrm{Cp} * \mathrm{M}\left(\mathrm{H}_{2} \mathrm{O}\right)_{3}\right]^{2+}$ complexes $(\mathrm{M}=\mathrm{Rh}$, Ir), increases the water exchange rate 
by 12-14 orders of magnitude. ${ }^{13} \mathrm{~A}{ }^{17} \mathrm{O}$ NMR investigation of the water exchange process for the $\mathrm{Cp}^{*} \mathrm{Mo}^{\mathrm{VI}}{ }_{\text {aq }}$ system as a function of $\mathrm{pH}$ is currently ongoing in our laboratories and will be reported in detail in a separate contribution, but we are already able to state that this appears to be an extremely fast process. Therefore, the mechanism of the low-pH transformation leading from $\mathrm{Cp}^{*} \mathrm{MoO}_{2}(\mathrm{OH})$ to $\left[\mathrm{Cp}^{*} \mathrm{MoO}_{2}\left(\mathrm{H}_{2} \mathrm{O}\right)\right]^{+}$may be formulated as path $b$ in Scheme 2, the slow step being the intramolecular proton transfer process, leading from the intermediate dihydroxo complex $\left[\mathrm{Cp}^{*} \mathrm{MoO}(\mathrm{OH})_{2}\right]^{+}$to the final product.

\section{(b) Protonation kinetics in the low $\mathrm{pH}$ regime}

In an effort to determine the first acid dissociation constant of $\left[\mathrm{Cp}^{*} \mathrm{MoO}(\mathrm{OH})_{2}\right]^{+}\left(\mathrm{p} K_{\mathrm{a} 1}\right)$, the acidification kinetics of $\left[\mathrm{Cp}^{*} \mathrm{MoO}_{3}\right]^{-}$was studied at low $\mathrm{pH}$ (down to zero), where the complex is present in the $\left[\mathrm{Cp}^{*} \mathrm{MoO}_{2}(\mathrm{OH})\right]$ form $\left(\mathrm{p} K_{\mathrm{a} 2}=3.65\right.$, see Figure 1). Consistent with the previous study, ${ }^{21}$ acidification kinetics showed a linear $\left[\mathrm{H}^{+}\right]$dependence up to $0.35 \mathrm{M}(\mathrm{pH}=0.45)$, but a slight saturation effect was visible at concentrations up to $1 \mathrm{M}(\mathrm{pH}$ down to 0$)$ as shown in Figure 3 . This behavior is fully consistent with the previously established scheme (Figure 1), because the rate law for the acidification reaction can be expressed as in Equation 2 (the equilibrium $K_{\mathrm{a} 1}$ is rapidly maintained on the time scale of $k_{-1}$ and $\left.k_{-2}\right){ }^{21}$ At low $\left[\mathrm{H}^{+}\right]\left(K_{\mathrm{a} 1}{ }^{-1}\left[\mathrm{H}^{+}\right]<<1\right)$, the rate law further simplifies to Equation 3 , which accounts for the linear dependence observed under such conditions. The small intercept could be ascribed to a minor contribution of the parallel k-1 path. It is useful to remind the reader here that at low $\mathrm{pH}$ the $k_{-1}$ pathway, corresponding to direct loss of $\mathrm{OH}^{-}$from $\mathrm{Cp}^{*} \mathrm{MoO}_{2}(\mathrm{OH})$, should be negligible $\left(k_{-1}=\right.$ $6.32 \cdot 10^{-7} \mathrm{~s}^{-1}$ ) compared to the $k_{-2}$ pathway, correponding to protonation and isomerization of the 
$\left[\mathrm{Cp} * \mathrm{MoO}(\mathrm{OH})_{2}\right]^{+}$intermediate, e.g. $\mathrm{k}_{-2} \mathrm{~K}_{\mathrm{a} 1}{ }^{-1}\left[\mathrm{H}^{+}\right]=1.73 \mathrm{~s}^{-1}$ at $\mathrm{pH}$ 1. Alternatively, the intercept can also be due to a contribution of the back reaction. i.e. the $\mathrm{k}_{2}$ path.

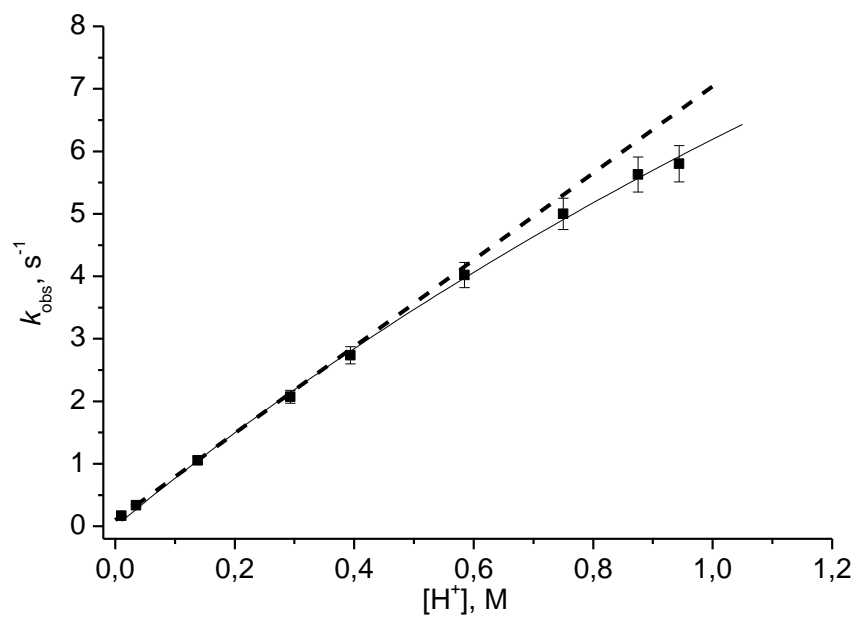

Figure 3. Plots of $k_{\text {obs }}$ versus $\left[\mathrm{H}^{+}\right]$for the acidification of $\left[\mathrm{Cp}^{*} \mathrm{MoO}_{3}\right]^{-}$with $\mathrm{HNO}_{3}$ in the range 0.01 to $0.95 \mathrm{M}$. Experimental conditions; $\left[\mathrm{Cp}^{*}{ }_{2} \mathrm{Mo}_{2} \mathrm{O}_{5}\right]=4 \times 10^{-4} \mathrm{M}, \lambda_{\text {det }}=390 \mathrm{~nm}, 20 \% \mathrm{MeOH}-$ $\mathrm{H}_{2} \mathrm{O}$, temp $=25^{\circ} \mathrm{C}, \mu_{\mathrm{tot}}=1 \mathrm{M}$ (adjusted with $\mathrm{NaNO}_{3}$ ).

$k_{\mathrm{obs}}=\left\{k_{-1}+k_{-2} K_{\mathrm{a} 1}^{-1}\left[\mathrm{H}^{+}\right]\right\} /\left\{1+K_{\mathrm{a} 1}^{-1}\left[\mathrm{H}^{+}\right]\right\}$

Equation 2

$$
k_{\mathrm{obs}} \sim k_{-1}+k_{-2} K_{\mathrm{a} 1}^{-1}\left[\mathrm{H}^{+}\right] \quad \text { (if }\left[\mathrm{H}^{+}\right] \text {small) }
$$

\section{Equation 3}

The fit of the data in Figure 3 with the expression of Equation 4, for which the small contribution of the intercept was ignored, resulted in $k_{-2}=28 \pm 1 \mathrm{~s}^{-1}\left(\log k_{-2}=1.44\right)$ and $K_{\mathrm{a} 1}=3.6 \pm 0.6 \mathrm{M}$, from which 
$\mathrm{p} K_{\mathrm{a} 1}=-0.56$. It follows that $k_{-2}$ is almost 8 orders of magnitude larger than $k_{-1}$ and that $\Delta \mathrm{p} K_{\mathrm{a}}\left(i . e . \mathrm{p} K_{\mathrm{a} 2^{-}}\right.$ $\left.\mathrm{p} K_{\mathrm{a} 1}\right)=4.1$. These values are consistent with expectations, since as mentioned above the $\Delta \mathrm{p} K_{\mathrm{a}}$ of a typical inorganic diprotic oxoacid is $\geq 4$. Thus, the new results described here fully confirm the validity of the previously proposed kinetic scheme (Figure 1), where a rapid pre-equilibrium protonation precedes a slow step, which is now known to be the intramolecular proton transfer, see next sections. It is worth to mention that the proton transfer to the oxo ligands in compound $\mathrm{Re}(\mathrm{O}) \mathrm{I}(2,7$-nonadiyne $)$ by $\mathrm{CF}_{3} \mathrm{SO}_{3} \mathrm{H}$ in $\mathrm{MeCN}$ was shown to be relatively slow $\left(11.9 \mathrm{M}^{-1} \mathrm{~s}^{-1}\right.$ at $\left.-40^{\circ} \mathrm{C}\right) .^{31}$

$k_{\mathrm{obs}} \sim k_{-2} K_{\mathrm{a} 1}^{-1}\left[\mathrm{H}^{+}\right] /\left\{1+K_{\mathrm{a} 1}^{-1}\left[\mathrm{H}^{+}\right]\right\} \quad$ (if $k_{-1}$ negligible)

\section{Equation 4}

It should be noted that the individual values of $K_{\mathrm{a} 1}$ and $k_{-2}$ obtained by the above analysis give rise to a ratio $k_{-2} / K_{\mathrm{a} 1}=7.8$, in relatively good agreement with the previously determined value (17.2). ${ }^{21}$ The discrepancy may be attributed to the difference in ionic strength used in these studies. However, one point remains to be discussed on the thermodynamics of the system, before we can turn to the kinetics. The combination of the individual rate constants for the tautomerization of the cationic system in both directions $\left(k_{2}\right.$ and $k_{-2}$ as shown in Scheme 3) yields the tautomerization equilibrium constant, $K_{2}=k_{2} / k_{-2}=$ $1.8 \cdot 10^{-5}$, which corresponds to a free energy difference of $6.5 \mathrm{kcal} \mathrm{mol}^{-1}$ in favor of the oxo aqua isomer. The combination of this value with the experimentally determined $\mathrm{p} K_{\mathrm{a} 1}$ value $(-0.56)$ according to the thermodynamic cycle shown in Scheme 3 (the deprotonation of the two isomeric cations affords the same neutral hydroxo complex) yields the thermodynamic proton dissociation constant of the dioxo aqua species, $K_{\mathrm{a} 1}{ }^{\prime}=6.5 \cdot 10^{-5} \mathrm{M}\left(\mathrm{p} K_{\mathrm{a} 1}{ }^{\prime}=4.19\right)$. This compares well with the value calculated from the $k_{-2} / K_{\mathrm{a} 1}$ determined in the previous study $\left(K_{\mathrm{a} 1}{ }^{\prime}=2.9 \cdot 10^{-5} \mathrm{M} ; \mathrm{p} K_{\mathrm{a} 1}{ }^{\prime}=4.54\right)$. Note that this value is also given by 
the expression $\left(k_{+1} / k_{-1}\right) K_{\mathrm{s}}$, from the thermodynamic cycle in Figure 1. At first sight, it may appear unreasonable that the first acid dissociation constant of this aqua complex is weaker than the second one. However, this observation can be rationalized if the water ligand is extensively dissociated due to the labilization caused by the $\mathrm{Cp}^{*}$ chelate as referred to above. In this case, the calculated $\mathrm{p} K_{\mathrm{a} 1}$ ' value must be treated as an apparent $\mathrm{p} K_{\mathrm{a}}$ value since it includes the equilibrium constant for the dissociation of water, which is expected to be large in order to offset the observed $\mathrm{p} K_{\mathrm{a}}$ value. Thus the effective thermodynamic acidity of the cationic complex is a weighted average of the coordinated water molecule acidity, which is expected to be intrinsically very high, and the acidity of the free water molecule $\left(\mathrm{p} K_{\mathrm{a}}=15.6\right)$. The hypothesis of an extensive water dissociation from the cationic complex is not inconsistent with the computational study, since the water adduct is calculated as only $10.1 \mathrm{kcal} / \mathrm{mole}$ more stable than the dissociated species according to the CPCM, but this calculation does not consider explicit interactions of the adduct and the separate fragments with additional water molecules. For instance, the stabilization of a water molecule by hydrogen bonding to additional water molecules is expected to contribute significantly to the equilibrium energetics (the solvation free energy of a water molecule in water has recently been estimated at $-6.3 \mathrm{kcal} / \mathrm{mol}){ }^{32}$ It is also interesting to recall that an electrospray mass spectrometric investigation of a $\mathrm{H}_{2} \mathrm{O}-\mathrm{MeOH}$ solution of $\mathrm{Cp}^{*} \mathrm{Mo}^{\mathrm{VI}}$ at low $\mathrm{pH}$ (ca. 4 and 1) revealed the presence of both $\mathrm{Cp}^{*} \mathrm{MoO}_{2}{ }^{+}$and $\mathrm{Cp}^{*} \mathrm{MoO}_{2}\left(\mathrm{H}_{2} \mathrm{O}\right)^{+}$species, as well as the related $\mathrm{Cp}^{*} \mathrm{MoO}_{2}(\mathrm{MeOH})^{+}$adduct. ${ }^{33,34}$ Whether the rapid equilibrium highlighted at the left hand side of Scheme 3 involves only species $\mathrm{Cp}^{*} \mathrm{MoO}_{2}{ }^{+}$and $\mathrm{Cp}^{*} \mathrm{MoO}_{2}\left(\mathrm{H}_{2} \mathrm{O}\right)^{+}$, or whether also a methanol solvate is present, does not affect the measured values of all rate and equilibrium constants, nor their significance. 


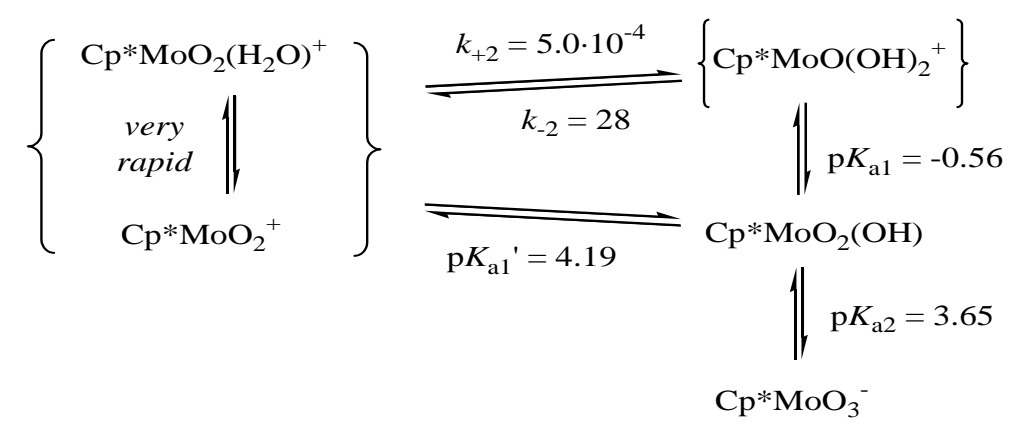

\section{Scheme 3}

In general it is expected that ground state labilization caused by metal-carbon bonds in the trans position to coordinated water molecules will not only drastically accelerate the water exchange process, but will also significantly increase the $\mathrm{pK}_{\mathrm{a}}$ value of the coordinated water as found in the present case. Bond weakening of the $\mathrm{M}-\mathrm{OH}_{2}$ bond will cause a decrease in the acidity of the coordinated water molecule. ${ }^{7}, 14$ In addition, the bond strength will follow the order $\mathrm{M}=\mathrm{O}>\mathrm{M}-\mathrm{OH}>\mathrm{M}-\mathrm{OH}_{2}$ as mentioned before. Thus, the combination of bond labilization and $\mathrm{pH}$ will control the lability of coordinated water and lead to apparent $\mathrm{pK}_{\mathrm{a}}$ values that seem to be 'abnormal'.

It is also interesting to analyze the $\mathrm{Cp}^{*} \mathrm{Mo}^{\mathrm{VI}}$ system in terms of the isolobal analogy between the $\mathrm{O}^{2-}$ and $\mathrm{Cp}^{*-}$ ligands. Thus, the $\mathrm{Cp}^{*} \mathrm{MoO}_{2}{ }^{+}$system is isolobally related to $\mathrm{MoO}_{3}, \mathrm{Cp}^{*} \mathrm{MoO}_{2}(\mathrm{OH})$ to $\mathrm{HMoO}_{4}^{-}$, and $\mathrm{Cp}^{*} \mathrm{MoO}_{3}{ }^{-}$to $\mathrm{MoO}_{4}{ }^{2-}$. Interestingly, while the $\mathrm{MoO}_{4}{ }^{2-}$ and $\mathrm{HMoO}_{4}^{-}$are always described as tetrahedral ions, aqueous $\mathrm{MoO}_{3}$ is described as having coordination number 6 (either as $\mathrm{MoO}_{3}\left(\mathrm{H}_{2} \mathrm{O}\right)_{3}$ or $\left.\mathrm{MoO}_{2}(\mathrm{OH})_{2}\left(\mathrm{H}_{2} \mathrm{O}\right)_{2}\right)$, possibly because an octahedral environment is found for $\mathrm{MoO}_{3}{ }^{35}$ as well as for its water adduct $\mathrm{MoO}_{3} \cdot 2 \mathrm{H}_{2} \mathrm{O},{ }^{36}$ in the solid state. However, equilibria with 5- or 4-coordinate species may in fact exist. A comparison between the $\mathrm{pK}_{\mathrm{a}}$ of $\mathrm{HMoO}_{4}{ }^{-}(3.48)^{4}$ and $\mathrm{Cp}^{*} \mathrm{MoO}_{2}(\mathrm{OH})(3.65)$ suggests that the $\mathrm{Cp}^{*-}$ ligand is a marginally better electron donor than the isolobal $\mathrm{O}^{2-}$ ligand for this system in an aqueous solvent. This means that the Mo center is electron-richer in $\mathrm{Cp}^{*} \mathrm{MoO}_{2}{ }^{+}$than in $\mathrm{MoO}_{3}$ as supported by the 
Mulliken charges in Mo atom $(+1.38$ vs. +1.88$)$. In combination with the greater steric bulk of the Cp* ligand vs. the oxo ligand, this may lead to a weaker interaction between $\left[\mathrm{Cp} * \mathrm{MoO}_{2}\right]^{+}$and water.

\section{(c) Activation parameters for the low-pH transformation}

The temperature and pressure dependence of the acidification process for the protonation reaction in the low acidity range have also been investigated. The data were collected only in the $\mathrm{pH}$ range where the rate depends linearly on $\left[\mathrm{H}^{+}\right]$, see Figure 4. The obtained activation parameters are $\Delta H^{\ddagger}$ slope $=5.1 \pm 0.1$ kcal mol ${ }^{-1}$ and $\Delta S_{\text {slope }}^{\ddagger}=-37 \pm 1 \mathrm{cal} \mathrm{mol}^{-1} \mathrm{~K}^{-1}$. The double logarithmic plots (logk vs. $\left.\mathrm{pH}\right)$ are linear with slopes very close to unity, demonstrating that the intercept plays a minor role in fitting the data.
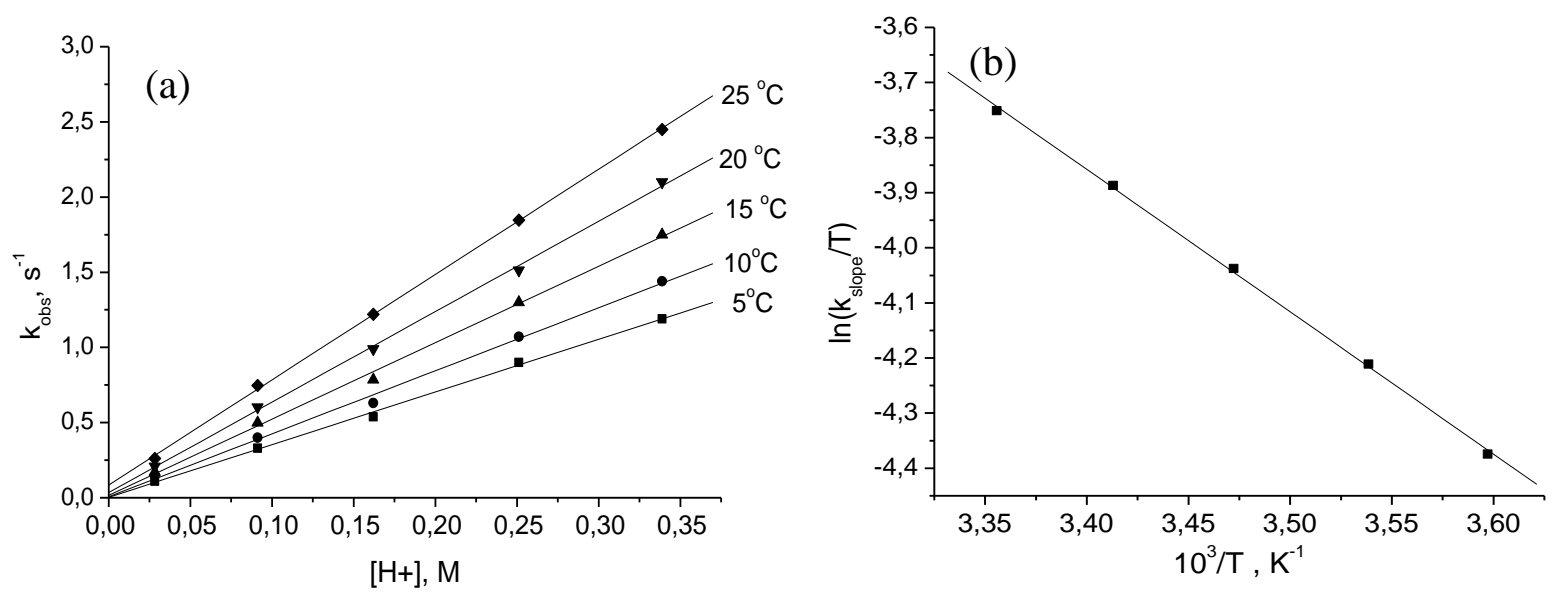

Figure 4. (a) Plots of $k_{\text {obs }}$ versus $\left[\mathrm{H}^{+}\right]$for the acidification of $\left[\mathrm{Cp}^{*} \mathrm{MoO}_{3}\right]^{-}$with $\mathrm{HNO}_{3}$ in the temperature range $5-25^{\circ} \mathrm{C}$ measured by stopped-flow. (b) Corresponding Eyring plot for the slope in (a). Experimental conditions; $\left[\mathrm{Cp}^{*}{ }_{2} \mathrm{Mo}_{2} \mathrm{O}_{5}\right]=4 \times 10^{-4} \mathrm{M}, \lambda_{\operatorname{det}}=390 \mathrm{~nm}, 20 \% \mathrm{MeOH}-\mathrm{H}_{2} \mathrm{O}, \mu_{\mathrm{tot}}=$ $1 \mathrm{M}$ (adjusted with $\left.\mathrm{NaNO}_{3}\right)$. 
The pressure dependence of the reaction was studied at $0.4 \mathrm{M}$ acid for which the data are shown in Figure 5. The obtained activation parameter, $\Delta V_{\text {slope }}^{\ddagger}-9.1 \pm 0.2 \mathrm{~cm}^{3} \mathrm{~mol}^{-1}$. The activation parameters for the slope of the plots in Figure 4 and Figure 5 represent those for $k_{-2} / K_{\mathrm{a} 1}$. Since nothing is presently known about the temperature dependence of $K_{\mathrm{a} 1}$, it is difficult to speculate about the meaning of the reported activation parameters. It is reasonable to speculate that $K_{\mathrm{a} 1}$ should not show a significant pressure dependence since it involves no changes in electrostriction and at the most can be slightly positive. The overall significantly negative activation entropy and volume values favor a process in which significant bond formation or charge creation occurs. According to the slow reaction for path (b) of Scheme 2, formation of the aqua complex involves bond formation between $\mathrm{OH}$ and $\mathrm{H}$, as well as shortening of the Mo-O bond during conversion of $\mathrm{Mo}-\mathrm{OH}$ to $\mathrm{Mo}=\mathrm{O}$. These processes are suggested to account for the observed volume collapse and decrease in entropy on going to the transition state.

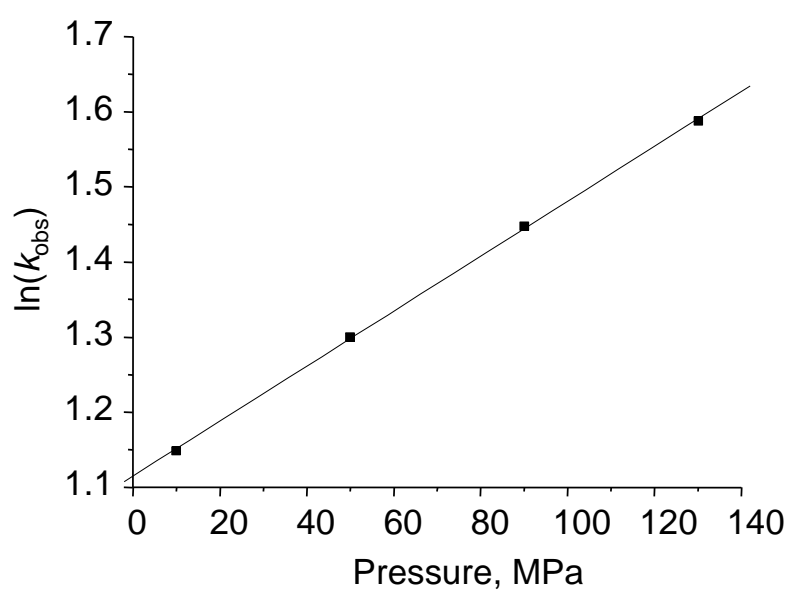

Figure 5. Plot of $\ln \left(k_{\mathrm{obs}}\right)$ versus pressure for the acidification of $\left[\mathrm{Cp} * \mathrm{MoO}_{3}\right]^{-}$with $\mathrm{HNO}_{3}$ in the range 10 $-130 \mathrm{MPa}$. Experimental conditions; $\left[\mathrm{Cp}^{*}{ }_{2} \mathrm{Mo}_{2} \mathrm{O}_{5}\right]=4 \times 10^{-4} \mathrm{M},\left[\mathrm{H}^{+}\right]=0.4 \mathrm{M}, \lambda_{\mathrm{det}}=390 \mathrm{~nm}$, $20 \% \mathrm{MeOH}-\mathrm{H}_{2} \mathrm{O}$, temp $=25{ }^{\circ} \mathrm{C}, \mu_{\text {tot }}=1 \mathrm{M}$ (adjusted with $\mathrm{NaNO}_{3}$ ).

\section{(d) Computational study of the intramolecular proton transfer process}


In order to validate the intramolecular proton transfer mechanism and find the possible origin of the negative activation parameters (entropy and volumes), we carried out calculations on the initial (1a) and end product (2a) of Equation 5, as well as on the transition state (ts1a), in the absence and in the presence of additional water molecules. The gas phase and water solution energy profiles obtained in the absence of additional water molecules are shown in Figure 6, whereas the optimized 1a and ts1a species are shown in Figure 7. The barrier height is quite high, having a value of $43.1 \mathrm{kcal} / \mathrm{mol}$ in the gas phase, whereas the reaction is endoergic by $10.6 \mathrm{kcal} / \mathrm{mol}$. Both results disagree with the experimental evidence, since the isomerization process is rather facile and the oxo-aqua complex is the thermodynamically more stable product. When the non-specific solvent effects are accounted for by use of the CPCM method, the barrier is nearly the same $(43.9 \mathrm{kcal} / \mathrm{mol})$, whereas the reaction is endoergic by $7.2 \mathrm{kcal} / \mathrm{mol}$, so the energetic difference has decreased by $3.4 \mathrm{kcal} / \mathrm{mol}$ by the inclusion of the solvent dielectric effects. Concerning the free Gibbs energy values (in the gas phase), they are very similar to the potential energy ones, for example, the difference between $\mathbf{1 a}$ and $\mathbf{2 a}$ is of $10.6 \mathrm{kcal} / \mathrm{mol}$ in potential energy whereas the free energy difference is $9.9 \mathrm{kcal} / \mathrm{mol}$. The high activation barrier is probably related to the distortion of the $\mathrm{OMoO}$ fragment as reflected in the large decrease in the O-Mo-O angle on going from 1a (106.8 ${ }^{\circ}$ to the transition state structure ts1a $\left(71.3^{\circ}\right)$. The transition state is also characterised by distances of $1.221 \AA$ and $1.276 \AA$ for the $\mathrm{O}-\mathrm{H}$ bonds being broken and formed, respectively, when going from $\mathbf{1 a}$ to $2 \mathbf{a}$. Thus, the old $\mathrm{O}-\mathrm{H}$ bond is already almost fully broken, whereas the new one has not yet formed to a significant extent, and the two Mo-O bond distances have intermediate values between those of the corresponding distances in the starting and final compounds. In conclusion, the intramolecular proton transfer implies a remarkable change in the geometry and this is associated with a high energetic cost. 


$$
\left[\mathrm{Cp} * \mathrm{MoO}(\mathrm{OH})_{2}\right]^{+}(\mathbf{1 a}) \longrightarrow\left[\mathrm{Cp} * \mathrm{MoO}_{2}\left(\mathrm{H}_{2} \mathrm{O}\right)\right]^{+}(\mathbf{2 a})
$$

\section{Equation 5}

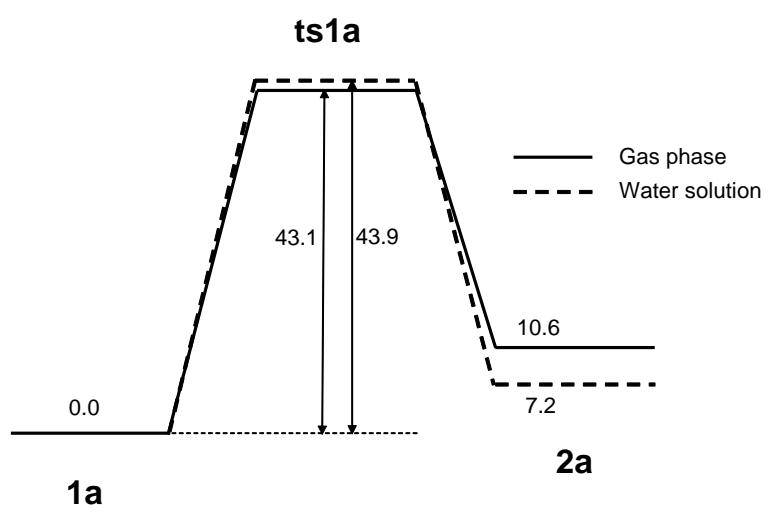

Figure 6. Relative energy profile (in $\mathrm{kcal} \mathrm{mol}^{-1}$ ) in gas phase and water solution for the starting complex(1a), transition state (ts1a) and product (2a) of Equation 5.

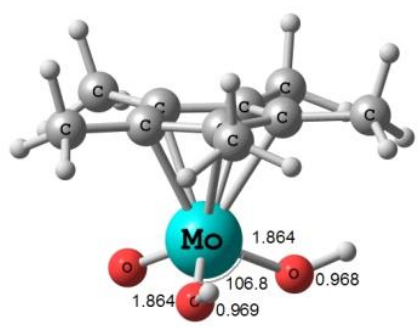

$1 \mathrm{a}$

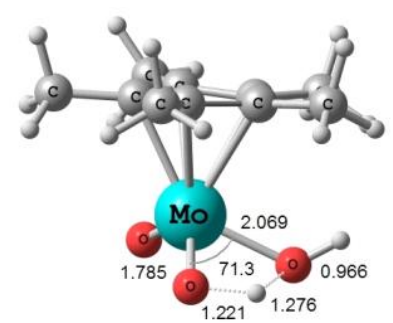

ts1a

Figure 7. Optimized structures of the dihydroxo complex (1a) and the proton transfer transition state (ts1a) of Equation 5 (distances in $\AA$; angles in degrees).

In order to further probe the mechanistic details of this reaction, we considered that the explicit inclusion of water molecules could afford an easier proton transfer pathway, as the system contains both donor and acceptor sites for the establishment of hydrogen bonds with water molecules. Many theoretical works have already reported the active participation of water chains in tautomerization ${ }^{37-39}$ and proton 
exchange processes. ${ }^{40,41}$ The mechanism is described as a water-assisted reaction in which one or more water molecules act as bifunctional catalyst. Recent theoretical studies of the tautomerization process between the hydrated oxide, $\left[\mathrm{MO}\left(\mathrm{H}_{2} \mathrm{O}\right)\right]^{+}$, and the dihydroxide $\left[\mathrm{M}(\mathrm{OH})_{2}\right]^{+}$cations $(\mathrm{M}=\mathrm{V}, \mathrm{Nb}$ and $\mathrm{Ta})$ also point out that the participation of water acting as proton donor and acceptor can effectively lower the barrier height for the isomerization process. ${ }^{42}$ The same water-catalysis has been found for the isomerization of $\mathrm{UO}_{2}(\mathrm{OH})_{2} \cdot{ }^{43}$ The resulting energy profiles with one additional water molecule are shown in Figure 8. In Figure 9 the main geometric characteristics of the optimized structures are depicted. First of all, the interaction of the additional water molecule with systems $\mathbf{1 a}$ and $\mathbf{2 a}$ gives rise to a significant energetic stabilization (15.5 and $8.1 \mathrm{kcal} \mathrm{mol}^{-1}$ in the gas phase and in water solution, respectively, for the dihydroxo complex $\mathbf{1 b} ; 21.0$ and $11.3 \mathrm{kcal} \mathrm{mol}^{-1}$ under the same conditions for the oxo aqua complex $\mathbf{2 b}$ ). The stabilization of $\mathbf{2 b}$ is slightly greater than that of $\mathbf{1 b}$, which renders the isomerization process less endothermic relative to the situation of the isolated system $\left(\Delta \mathrm{E}=+5.1\right.$ and $+4.0 \mathrm{kcal} \mathrm{mol}^{-1}$ in the gas phase and in water solution). The corresponding free energy difference in the gas phase is $+3.4 \mathrm{kcal} \mathrm{mol}^{-1}$. This change seems related to the stronger hydrogen bonding of water with the proton of the aqua ligand in $\mathbf{2 b}$, relative to the proton of one of the two hydroxo ligands in $\mathbf{1 b}$ (as measured by the greater $\mathrm{O}-\mathrm{H}$ bond elongation, 1.025 vs. $0.997 \AA$, and by the shorter $\mathrm{O} \cdots \mathrm{H}$ distance, 1.511 vs. $1.655 \AA$ ). The most dramatic effect relative to the water free system, however, is observed at the relative barrier height, which is now only $12.7 \mathrm{kcal} \mathrm{mol}^{-1}$ (vs. 43.1 without water) in the gas phase and only $10.3 \mathrm{kcal} \mathrm{mol}^{-1}$ (vs. 43.9 without water) in solution above the $\mathbf{1 b}$ species. This effect is related to the ability of the additional water molecule to act, at the same time, as a proton acceptor for the donating $\mathrm{O}-\mathrm{H}$ ligand and as a proton donor for the receiving $\mathrm{O}-\mathrm{H}$ ligand, thereby mediating the proton transfer. Both hydrogen-bonding interactions are established at the level of the transition state (ts1b) giving a six-membered transition state, as shown in Figure 9. The most likely cause of such dramatic decrease in activation barrier is the smaller distortion of 
the $\mathrm{OMoO}$ fragment in the transition states, as evidenced by the wider O-Mo-O angle in ts1b $\left(92.5^{\circ}\right)$ in comparison with the $71.3^{\circ}$ value optimized for the ts1a structure. The optimized O-Mo-O angles in $\mathbf{1 b}$ and $\mathbf{2 b}$, on the other hand, are essentially unchanged relative to those of $\mathbf{1 a}$ and $\mathbf{2 a}$. Thus, the structural rearrangement in ts1b is not as marked as in ts1a, with respect to the relative reactants. It is worth to mention that a very slow rate of intramolecular proton transfer was reported for complex $\operatorname{Re}(\mathrm{O})\left({ }^{18} \mathrm{OH}\right)(\mathrm{MeC} \equiv \mathrm{CMe})_{2}$ in benzene solution. ${ }^{44}$ Although the rate of transformation was shown not to strongly depend on the presence or absence of stoichiometric amounts of ethanol, trace amounts of $\mathrm{CF}_{3} \mathrm{SO}_{3} \mathrm{H}$ strongly accelerate the reaction. It is possible that the transformation could also be accelerated by excess water. Another slow intramolecular proton transfer process was reported for trans$\left[\mathrm{Ru}^{\mathrm{IV}}(\operatorname{tpy})(\mathrm{O})\left(\mathrm{O}=\mathrm{P}(\mathrm{Ph})_{2} \mathrm{CH}_{2} \mathrm{CH}_{2} \mathrm{PPh}_{2}\right)\left(\mathrm{H}_{2} \mathrm{O}\right)\right]^{2+}$ in $\mathrm{MeCN}$ solution. ${ }^{45}$

Another noteworthy characteristic of ts1b is that the proton originating from the donating $\mathrm{O}-\mathrm{H}$ group has already migrated onto the water molecule (1.088 $\AA$ ), whereas the proton that eventually ends up in the aqua ligand is still bonded to the added water molecule (1.026 $\AA$ ). These distances suggest that the transition state involves the interaction between a hydronium ion $\left(\mathrm{H}_{3} \mathrm{O}^{+}\right)$and the neutral $\mathrm{Cp}^{*} \mathrm{MoO} 2(\mathrm{OH})$ molecule, through the establishment of two hydrogen bonds $(1.382 \AA$ to the oxo ligand and $1.591 \AA$ to the hydroxo ligand). We have reported a similar transition-state in hydrogenation performed by gold catalysts for the heterolytic cleavage of $\mathrm{H}_{2}$ assisted by a solvent molecule (ethanol). ${ }^{46}$ In conclusion, the explicit consideration of a water molecule confirms the feasibility of the rearrangement of $\mathbf{1 b}$ to $\mathbf{2 b}$ by solvent assisted intramolecular proton transfer.

$$
\left[\mathrm{Cp} * \mathrm{MoO}(\mathrm{OH})_{2}\right]^{+} \cdot \mathrm{H}_{2} \mathrm{O}(\mathbf{1 b}) \longrightarrow\left[\mathrm{Cp}^{*} \mathrm{MoO}_{2}\left(\mathrm{H}_{2} \mathrm{O}\right)\right]^{+} \cdot \mathrm{H}_{2} \mathrm{O}(\mathbf{2 b})
$$

\section{Equation 6}




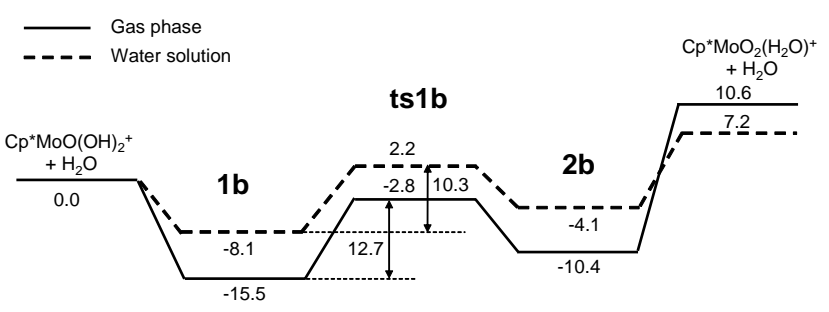

Figure 8. Relative energy profiles (in $\mathrm{kcal} \mathrm{mol}^{-1}$ ) in gas phase and water solution for the starting complex (1b), transition state (ts1b) and product (2b) of Equation 6.

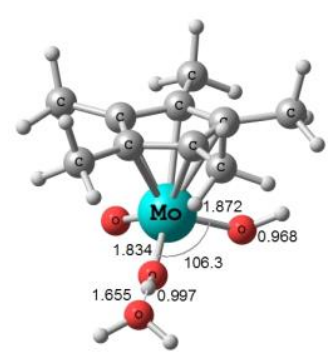

$1 \mathrm{~b}$

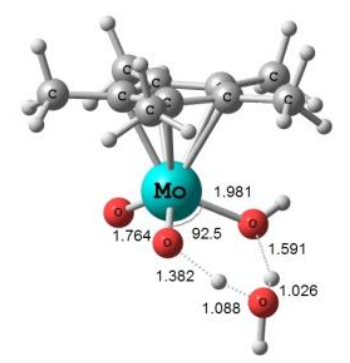

ts1b

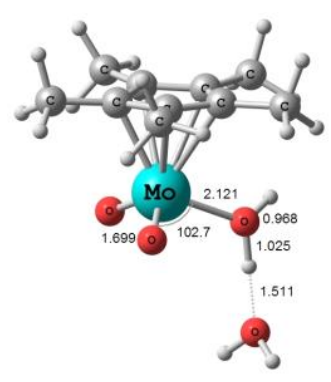

$2 \mathbf{b}$

Figure 9. Optimized structures of the starting complex (1b, above), transition state (ts1b, middle) and product (2b, below) of Equation 6 (distances in $\AA$; angles in degrees).

On the basis of the above results, we have imagined that the addition of a second water molecule could further lower the energy of the transition state. An eight-membered transition-state (ts1c) having two water molecules acting as proton and donor acceptors concurrently between the two complexes 1c and 2c (Equation 7) may further reduce the necessary geometric reorganization to reach the transition state. The resulting energy profiles in the gas phase and water solution on this system are shown in Figure 10 and the optimized structures for the related species are drawn in Figure 11. As already seen on going from the water-free to the $\mathrm{H}_{2} \mathrm{O}$ adduct, going from the mono to the bis(water) adduct further stabilizes the oxoaqua isomer relative to the dihydroxo isomer. The oxo-aqua complex is now only $1.4 \mathrm{kcal} \mathrm{mol}^{-1}$ less stable than the dihydro isomer in the gas phase ( $c f .5 .1$ and $10.6 \mathrm{kcal} \mathrm{mol}^{-1}$ for the mono(water) and water- 
free system, respectively), and actually more stable by a small margin $\left(0.4 \mathrm{kcal} \mathrm{mol}^{-1}\right)$ in water solution. The gas phase free energy is still in favor of the dihydroxo isomer, but only by $2.4 \mathrm{kcal} \mathrm{mol}^{-1}$. Undoubtedly, the correct relative energy can be obtained at this level of theory, provided the effect of the water solvation is considered by the explicit inclusion of a sufficient number of water molecules in the calculation. Although the relative free energy computed by including two water molecules is still a bit far from the experimental value of $6.5 \mathrm{kcal} \mathrm{mol}^{-1}$ in favor of the oxo aqua isomer, the explicit inclusion of water molecules in the calculations moves the energetic balance in the right direction. In conclusion, our calculations indicate an intrinsic preference of the system for the dihydroxide form (gas phase). The nonspecific interactions (continuum calculations) are not sufficient to reverse this stability order, whereas a reversal, in agreement with the experiment, is observed upon inclusion of the specific interactions (hydrogen bonds) with the water solvent. Undoubtedly, the correct relative energy can be obtained at this level of theory, provided the effect of the water solvation is considered by the explicit inclusion of a sufficient number of water molecules in the calculation.

$$
\left[\mathrm{Cp} * \mathrm{MoO}(\mathrm{OH})_{2}\right]^{+} \cdot 2 \mathrm{H}_{2} \mathrm{O}(\mathbf{1 c}) \longrightarrow\left[\mathrm{Cp}^{*} \mathrm{MoO}_{2}\left(\mathrm{H}_{2} \mathrm{O}\right)\right]^{+} \cdot 2 \mathrm{H}_{2} \mathrm{O}(\mathbf{2 c})
$$

\section{Equation 7}

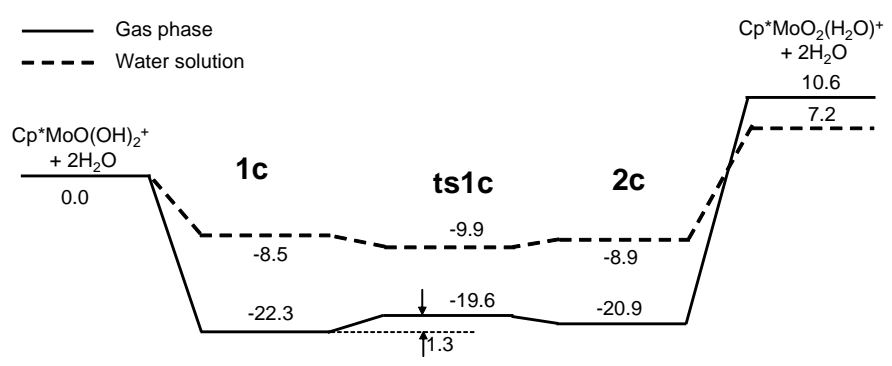

Figure 10. Relative energy profiles (in $\mathrm{kcal} \mathrm{mol}^{-1}$ ) in gas phase and water solution for the starting complex (1c) transition state (ts1c) and product (2c) of Equation 7. 


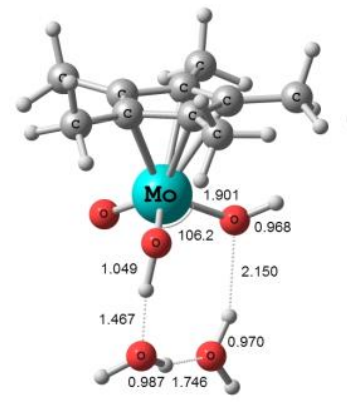

$1 c$

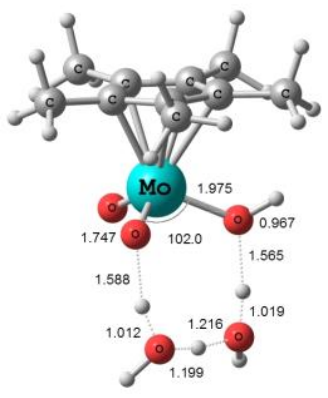

ts 1c

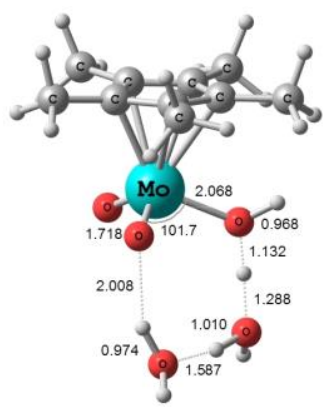

2c

Figure 11. Optimized structures of the starting complex (1c, above), transition state (ts1c, middle) and product (2c, below) of Equation 7 (distances in $\AA$; angles in degrees).

Concerning the energetic profile, the proton transfer barrier is now reduced to a very low value (1.3 $\mathrm{kcal} / \mathrm{mol}$ and $3.5 \mathrm{kcal} / \mathrm{mol}$ in potential and free energy, respectively). In CPCM single point calculations the energy of the transition-state is even lower than the corresponding reactant energy. We consider that this difference is within the error of the CPCM method. Compared to ts1b and ts1a, the structure of ts1c is characterized by an even wider O-Mo-O angle $\left(102.0^{\circ}\right)$. Now the Mo-O bonds barely have to bend in order to reach the suitable configuration for the proton transfer. The explicit inclusion of the two water molecules also has the effect of further weakening the O-H bonds for the hydroxo ligands (1.049 $\AA$ in $\mathbf{1 c}$, vs. $0.997 \AA$ in $\mathbf{1 b})$ and the aqua ligand $(1.132 \AA$ in $\mathbf{2 c}$, vs. $1.025 \AA$ in $\mathbf{2 b})$. Thus, the proton becomes effectively more transferred to the medium. As was the case for ts1b, the structure of ts1c may also be viewed as resulting from the hydrogen bonding interaction of a hydronium ion (in this case $\mathrm{H}_{5} \mathrm{O}_{2}{ }^{+}$) with neutral $\mathrm{Cp} * \mathrm{MoO}_{2}(\mathrm{OH})$, according to the observed pattern of $\mathrm{O}-\mathrm{H}$ and $\mathrm{O} \cdots \mathrm{H}$ distances.

For the sake of completion, we have pursued the study by adding a third water molecule to the system. In this case, however, the optimization of both the hydroxo and the oxo aqua isomers $\mathbf{1 d}$ and $\mathbf{2 d}$ resulted in an optimized structure where the water proton is completely transferred to the water cluster, 
which thereby becomes a $\mathrm{H}_{7} \mathrm{O}_{3}{ }^{+}$hydronium ion and interacts via hydrogen bonding with the neutral $\mathrm{Cp}^{*} \mathrm{MoO}_{2}(\mathrm{OH})$ complex, see Figure 12. These results confirm the trend reported in $\mathbf{2 b}$ and $\mathbf{2 c}$, where the $\mathrm{O}-\mathrm{H}$ bond became more elongated as more water molecules were added in the system. This trend reflects the acidity of the cationic species, thus a more water-rich environment favors the proton transfer to the medium. The two structures $\mathbf{1 d}$ and $\mathbf{2 d}$ are isomers in terms of the arrangement of the hydrogen-bonded water molecules. Structure $\mathbf{2 d}$ is more stable than $\mathbf{1 d}$ by $1.8 \mathrm{kcal} \mathrm{mol}^{-1}$ in water solution. It is interesting to note that the protonated water molecule $\left(\mathrm{H}_{3} \mathrm{O}^{+}\right)$interacts with the $\mathrm{OH}$ group in structure $\mathbf{2 d}$, whereas it prefers an oxo ligand in structure 1d. Although this difference is fairly small and the final point depends on the starting point in the optimization, this difference may be attributed to the fact that in $\mathbf{2 d}$ there is an additional hydrogen bond. Moreover, the $\mathrm{O}(\mathrm{OH})$ interacting with $\mathrm{H}_{3} \mathrm{O}^{+}$in $2 \mathbf{d}$ presents a more negative Mulliken charge than the $\mathrm{O}$ interacting with $\mathrm{H}_{3} \mathrm{O}^{+}$in $\mathbf{1 d}:-1.11$ vs. -0.89 .
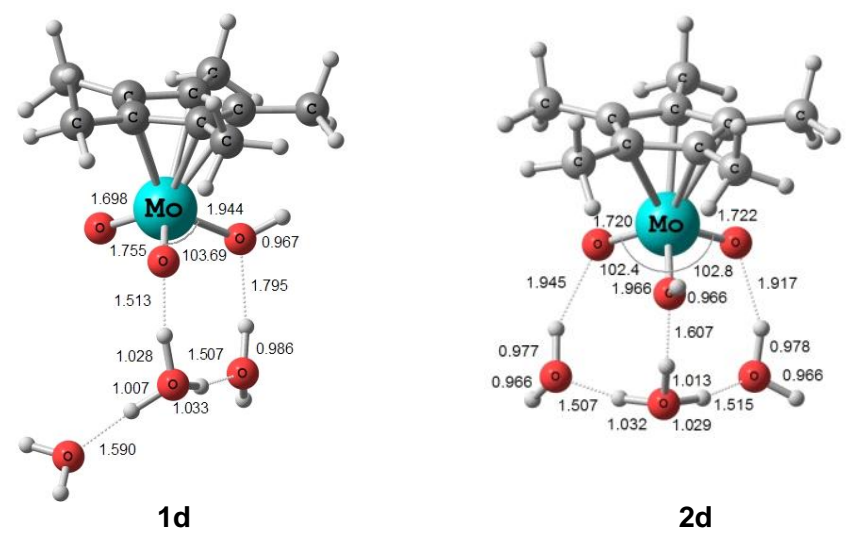

Figure 12. Optimized structure of $\mathbf{1 d}$ and $\mathbf{2 d}$, featuring the $\mathrm{Cp}^{*} \mathrm{MoO}_{2}(\mathrm{OH})$ molecule interacting with the $\left[\left(\mathrm{H}_{3} \mathrm{O}\right)\left(\mathrm{H}_{2} \mathrm{O}\right)_{2}\right]^{+}$cluster (distances in $\AA$; angles in degrees).

A comparison of all isomeric pairs shows that the aqua $\mathrm{O}-\mathrm{H}$ bond in the oxo aqua isomer systematically experiences a greater lengthening effect than the hydroxo $\mathrm{O}-\mathrm{H}$ bond in the dihydroxo 
isomer $(1.025 \AA$ in $\mathbf{2 b} v s .0 .997 \AA$ in $\mathbf{1 b}, 1.132 \AA$ in $\mathbf{2 c} v s .1 .049 \AA$ in $\mathbf{1 c}$; these distances are essentially identical in 1a and 2a). This suggests that $\left[\mathrm{Cp} * \mathrm{MoO}_{2}\left(\mathrm{H}_{2} \mathrm{O}\right)\right]^{+}$is intrinsically more acidic than its dihydroxo isomer, which may seem in contradiction with the experimental evidence (oxo aqua isomer: $\mathrm{p} K_{\mathrm{a}}=4.19$; dihydroxo isomer: $\left.\mathrm{p} K_{\mathrm{a}}=-0.56\right)$. However, as argued above, the high effective $\mathrm{p} K_{\mathrm{a}}$ value of $\left[\mathrm{Cp} * \mathrm{MoO}_{2}\left(\mathrm{H}_{2} \mathrm{O}\right)\right]^{+}$is proposed to result from an equilibrium with $\left[\mathrm{Cp} * \mathrm{MoO}_{2}\right]^{+}$and free $\mathrm{H}_{2} \mathrm{O}$. Thus, these computational results indirectly validate the water dissociation hypothesis.

The calculations agree with the experimental evidence that the cationic systems, $\left[\mathrm{Cp} * \mathrm{MoO}(\mathrm{OH})_{2}\right]^{+}$ and $\left[\mathrm{Cp}^{*} \mathrm{MoO}_{2}\left(\mathrm{H}_{2} \mathrm{O}\right)\right]^{+}$, can be deprotonated in a slightly acidic medium. However, the predominant species in very acidic media is a cationic complex. As a very simple way of modeling the effect of lowering the $\mathrm{pH}$, we have added an extra proton to the system, i.e. using the $\left[\mathrm{H}_{3} \mathrm{O}\left(\mathrm{H}_{2} \mathrm{O}\right)_{2}\right]^{+}$cluster as a model of the medium. The resulting system is dipositive. This is a rough simulation of a low $\mathrm{pH}$ aqueous solution but can give some insights of what occurs when increasing the acidity of the medium. Several theoretical studies have addressed the question of the nature of the hydronium species in solution and its solvation shell. ${ }^{47-50}$ The $\left[\mathrm{H}_{3} \mathrm{O}\left(\mathrm{H}_{2} \mathrm{O}\right)_{2}\right]^{+}$cluster has been used as a model of the hydronium species in solution in other reactions involving transition metal complexes. ${ }^{51,52}$ Different structures were optimized, exploring several starting points, and the various optimized species are shown in Figure 13. For species 1e and $\mathbf{2 e}$, the hydronium ion $\left(\mathrm{H}_{3} \mathrm{O}^{+}\right)$is located in the second coordination sphere, whereas species $\mathbf{1 e 2}, \mathbf{1 e} 3$ and $2 \mathbf{e} 2$ feature this ion in the first coordination sphere, directly interacting with the molybdenum complex. Obviously, these are not necessarily all the possible minima, but probably the most favored ones. 

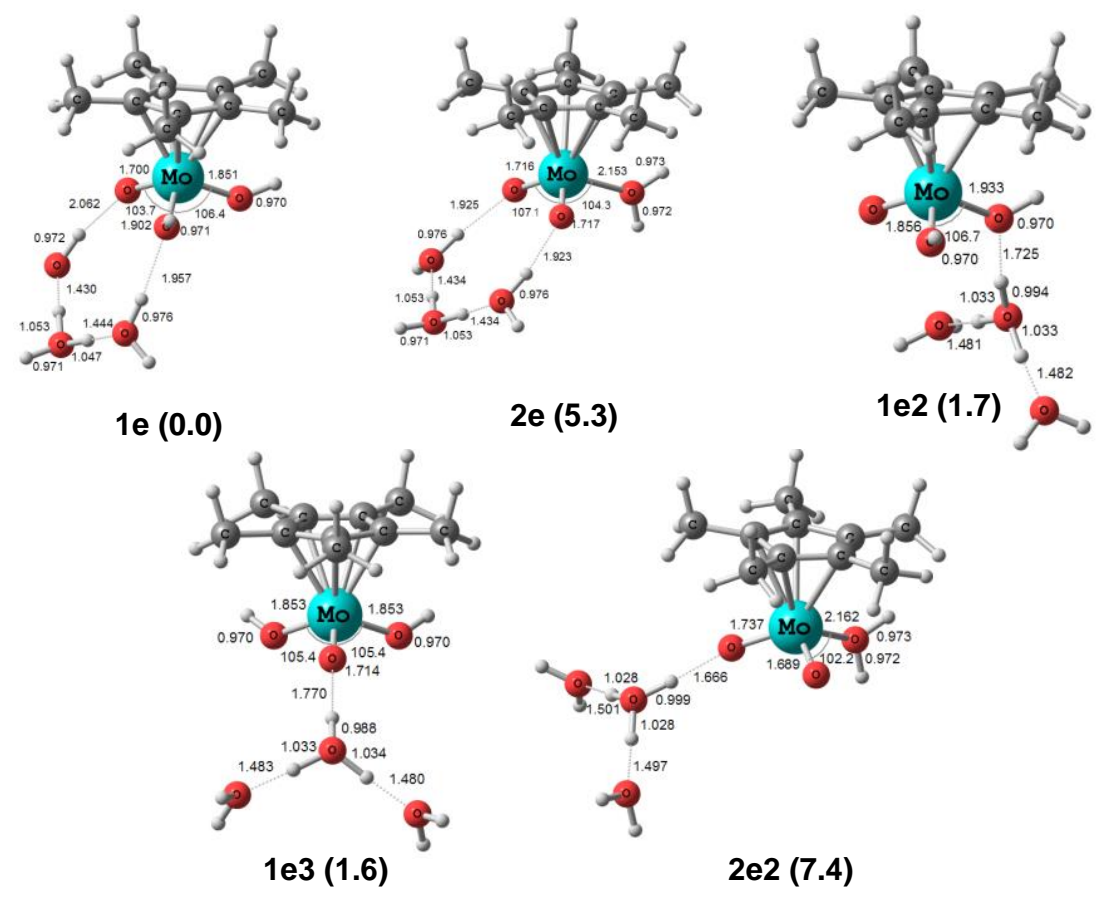

Figure 13. Optimised structures of the $\left[\mathrm{Cp} * \mathrm{MoO}(\mathrm{OH})_{2}\right]^{+}$and $\left[\mathrm{Cp}^{*} \mathrm{MoO}_{2}\left(\mathrm{H}_{2} \mathrm{O}\right)\right]^{+}$complexes interacting with the $\left[\left(\mathrm{H}_{3} \mathrm{O}\right)\left(\mathrm{H}_{2} \mathrm{O}\right)_{2}\right]^{+}$cluster (relative energies in $\mathrm{kcal} \mathrm{mol}^{-1}$ in parentheses).

In no case was the proton of the cationic complex $\left(\left[\mathrm{Cp}^{*} \mathrm{MoO}_{2}\left(\mathrm{H}_{2} \mathrm{O}\right)\right]^{+}\right.$or $\left.\left[\mathrm{Cp} * \mathrm{MoO}(\mathrm{OH})_{2}\right]^{+}\right)$ transferred to the medium, conversely of what occurred for the monopositive system with three water molecules. This is not a surprising result, the medium (modeled here as $\left[\mathrm{H}_{3} \mathrm{O}\left(\mathrm{H}_{2} \mathrm{O}\right)_{2}\right]^{+}$) being too acidic in the gas phase to accept an additional proton, because it has an excess of positive charge. Nevertheless, this approach gives a nice representation of what occurs when lowering the $\mathrm{pH}$ value because the cationic species become now favorable and can be obtained as real minima in the potential energy surface for both isomers.

Concerning the relative energies, placing the hydronium ion in the first coordination sphere carries an energy cost of ca. $2 \mathrm{kcal} / \mathrm{mol}$, relative to having it in the second sphere (e.g. going from 1e to $1 \mathbf{e} 2$ and $1 \mathbf{3} 3$ for the dihydroxo complex, and from $2 \mathbf{e}$ to $2 \mathbf{e} 2$ for the oxo aqua complex). On the other hand, the 
dihydroxo isomer is more stable than the oxo aqua species by $5.3 \mathrm{kcal} \mathrm{mol}^{-1}$ (1e vs. 2e structure). As discussed before, we believe that a larger number of water molecules (at least the complete first solvation sphere) should be included in order to reproduce the experimental relative stability.

The experimental data also show that the dominant species at $\mathrm{pH}>5$ is the anionic complex $\left[\mathrm{Cp}^{*} \mathrm{MoO}_{3}\right]^{-21}$ We suggest that when increasing the hydroxide concentration, the proton of the $\left[\mathrm{Cp}^{*} \mathrm{MoO}_{2}(\mathrm{OH})\right]$ complex can be easily transferred to hydroxide in solution, analogously to what occurs to one proton of the aqua complex when water molecules are added to the system. Nevertheless, although theoretical calculations reported here provide some relevant energy trends, geometries and activation barriers, a complete theoretical analysis of the species present in solution as a function of $\mathrm{pH}$ is beyond the scope of this study, mainly because of the intrinsic difficulty of simulating an aqueous solution at a given $\mathrm{pH}$. More information could be extracted from dynamics simulations.

\section{Conclusions}

A combination of kinetic and computational investigations on the $\mathrm{Cp}^{*} \mathrm{Mo}^{\mathrm{VI}}$ system in acidic aqueous medium has greatly improved our understanding of what factors regulate the properties of the oxo dihydroxo $\left(\left[\mathrm{Cp} * \mathrm{MoO}(\mathrm{OH})_{2}\right]^{+}\right)$and dioxo aqua $\left(\left[\mathrm{Cp}^{*} \mathrm{MoO}_{2}\left(\mathrm{H}_{2} \mathrm{O}\right)\right]^{+}\right)$isomers in solution. The computational study shows that the dihydroxo isomer is favored for the isolated system in the gas phase, but the subsequent introduction of the solvent model (by CPCM) and especially the explicit introduction of water molecules in the calculations attenuate and even reverse this stability trend. The study further suggests that the medium strongly affects the water dissociation energy cost from the dioxo aqua isomer (10.1 kcal mol ${ }^{-1}$ in water solution vs. $39.7 \mathrm{kcal} \mathrm{mol}^{-1}$ in the gas phase). A generalization of these trends suggests that the dihydroxo species for any given system have a better chance to be stable in apolar 
organic solvents, whereas a rearrangement to oxo complexes accompanied by water dissociation may be favored in stronger dielectric solvents.

The above trend also rationalizes the unusually low acidities that are sometimes found for high oxidation state cationic complexes. While the water ligand in the oxo aqua isomer, $\left[\mathrm{Cp}^{*} \mathrm{MoO}_{2}\left(\mathrm{H}_{2} \mathrm{O}\right)\right]^{+}$, is an intrinsically stronger proton donor than the hydroxo ligand in the dihydroxo isomer, $\left[\mathrm{Cp} * \mathrm{MoO}(\mathrm{OH})_{2}\right]^{+}$, the much lower observed acidity for the former $\left(\mathrm{p} K_{\mathrm{a}}=4.19 ;\right.$ ss. -0.56 for the latter) is related to a water dissociation equilibrium. In turn, this is related to the coordination sphere and particularly to how the ligands are able to satisfy the electron deficiency at the metal center upon loss of the water lone pair donation. In the present system the extremely high lability of the coordinated water molecule can be ascribed to the trans labilization effect of the $\mathrm{Cp}^{*}$ chelate, which in turn favors the formation of the dioxo complex and is responsible for the apparent high $\mathrm{p} K_{\mathrm{a}}$ value of the oxo aqua isomer. We are not aware of any other analogous study in the literature.

Concerning the isomerization mechanism leading from the dihydroxo to the oxo aqua species, the direct intramolecular proton transfer from the dihydroxo to the aqua complex can be ruled out due to the high calculated barrier for the direct proton transfer, viz. $43.9 \mathrm{kcal} \mathrm{mol}^{-1}$ including solvent effects. The assistance of either one or two water molecules renders proton transfer feasible by dramatically lowering the barrier height. The mechanism involving assistance by two water molecules even yields a lower energy for the transition state than for the reactant and product when including the CPCM, suggesting that this is indeed a very facile process. The assistance by amphiphilic external molecules, such as water, is increasingly found to be crucial to lower activation barriers of intramolecular proton transfer rearrangements. 
Acknowledgement. We gratefully acknowledge the European Commission for funding this work through the AQUACHEM Research Training Network (Contract n ${ }^{\circ}$ MRTN-CT-2003-503864). Financial support from the Spanish MEC through Project CTQ2005-09000-C02-01 and from Generalitat de Catalunya through grant 2005SGR00896 is gratefully acknowledged. A.C.-V. acknowledges the Spanish MEC for a FPU fellowship.

Supporting information available. Complete references 19, 51 and 56, and absolute energies and cartesian coordinates of the optimized structures. This material is available free of charge via the Internet at http://pubs.acs.org.

\section{Experimental Section}

Solution Preparation and Measurements. All chemicals used in this study were of analytical grade. The solution $\mathrm{pH}$ was controlled by using $\mathrm{HNO}_{3}$. The total ionic strength $(\mu)$ was kept constant at $1 \mathrm{M}$ with $\mathrm{NaNO}_{3}$. $\mathrm{pH}$ measurements were carried out on a Metrohm $623 \mathrm{pH}$ meter equipped with a Sigma glass electrode. UV-vis spectra were recorded in gastight cuvettes on a Shimadzu UV-2100 spectrophotometer equipped with a thermostated cell compartment CDS-260.

Stopped-flow kinetic measurements on the acidification $\left[\mathrm{Cp} * \mathrm{MoO}_{3}\right]^{-}$with $\mathrm{HNO}_{3}$ in the $\mathrm{pH}$ range from 0.025 to 0.35 were carried out using an Applied Photophysics SX-18MV stopped-flow spectrophotometer. $20 \% \mathrm{MeOH}-\mathrm{H}_{2} \mathrm{O}$ solutions of $\left[\mathrm{Cp} * \mathrm{MoO}_{3}\right]^{-}$were rapidly mixed with varying $\mathrm{pH}$ solution in a gas-tight syringe. The kinetics of the reaction was monitored at $390 \mathrm{~nm}$ where the change in absorbance is a maximum for the acidified molybdenum product. The rate constant for acidification was determined from the slope of linear plots of $k_{\text {obs }}$ versus $\left[\mathrm{H}^{+}\right]$, as described in more detail under Results and Discussion. All kinetic experiments were performed under pseudo-first order conditions, i.e., with at least 
10-fold excess of $\left[\mathrm{H}^{+}\right]$over the $\mathrm{Cp}^{*}{ }_{2} \mathrm{Mo}_{2} \mathrm{O}_{5}$ complex. Reported rate constants are the mean values of at least five kinetics runs, and the quoted uncertainties are based on the standard deviation. High-pressure stopped-flow studies were performed on a custom-built instrument (from 10 to $130 \mathrm{MPa}$ ). ${ }^{53}$ Kinetic traces were recorded on an IBM-compatible computer and analyzed with the use of OLIS KINFIT (Bogart, GA) set of programs.

Computational details. Calculations were carried out using the Gaussian 03 package ${ }^{54}$ at the DFT level by means of the B3LYP functional. ${ }^{55-57}$ For the Mo atom, the LANL2DZ pseudopotential ${ }^{58}$ was used with the addition of $\mathrm{f}$ polarisation functions. ${ }^{59}$ The $6-31 \mathrm{G}(\mathrm{d})$ basis set was used for $\mathrm{C}$ atoms whether for $\mathrm{O}$ atoms additional diffuse functions were added due to their anionic character $(6-31+G(d))$. For the hydrogens, the 6-31G(d,p) basis set was employed. IRC calculations were made in order to get the two minima linked by every transition-state. ${ }^{60-62}$

Solvent effects were included by means of CPCM single point calculations. ${ }^{63,64}$ Additional spheres were included for all the hydrogens except for the $\mathrm{Cp}^{*}$ hydrogens by means of the SPHEREONH option. Frequency calculations were made in order to get the free Gibbs energy. The temperature used was 298.15 K.

\section{References}

1 Cruywagen, J. J.; Heyns, J. B. B.; Rohwer, E. F. C. H., J. Inorg. Nucl. Chem. 1976, 38, 2033-2036.

2 Cruywagen, J. J.; Draaijer, A. G.; Rypstra, T., South African Journal of Chemistry 1988, 41, 89-96.

3 Castro-Garcia, S.; Pecquenard, B.; Bender, A.; Livage, J.; Julien, C., Ionics 1997, 3, 104-109.

4 Cruywagen, J. J.; Draaijer, A. G.; Heyns, J. B. B.; Rohwer, E. A., Inorg. Chim. Acta 2002, 331, 322-329.

5 Paffett, M. T.; Anson, F. C., Inorg. Chem. 1981, 20, 3967-72.

6 Cruywagen, J. J., Adv. Inorg. Chem. 2000, 49, 127-182.

7 Richens, D. T., Chem. Rev. 2005, 105, 1961-2002.

8 Bortolin, R.; Patel, V.; Munday, I.; Taulor, N. J.; Carty, A. J., J. Chem. Soc., Chem. Commun. 1985, 456-458.

9 Carney, M. J.; Walsh, P. J.; Bergman, R. G., J. Am. Chem. Soc. 1990, 112, 6426-6428.

10 Parkin, G.; Bercaw, J. E., Polyhedron 1988, 7, 2053-2082. 
Fettinger, J. C.; Kraatz, H.-B.; Poli, R.; Quadrelli, E. A., J. Chem. Soc., Dalton Trans. 1999, 497508.

Morales, D.; Pleune, B.; Poli, R.; Richard, P., J. Organometal. Chem. 2000, 596, 64-69.

Dadci, L.; Elias, H.; Frey, U.; Hoernig, A.; Koelle, U.; Merbach, A. E.; Paulus, H.; Schneider, J. S., Inorg. Chem. 1995, 34, 306-15.

Helm, L.; Merbach, A. E., Chem. Rev. 2005, 105, 1923-1959.

Poli, R., Chem. Eur. J. 2004, 10, 332-341.

Reis, P. M.; Romão, C. C.; Royo, B., J. Chem. Soc., Dalton Trans. 2006, 1842-1846.

Abrantes, M.; Santos, A.; Mink, J.; Kühn, F.; Romão, C., Organometallics 2003, 22, 2112-2118.

Zhao, J.; Santos, A. M.; Herdtweck, E.; Kühn, F. E., J. Mol. Catal. A 2004, 222, 265-271.

Martins, A. M., et al., Organometallics 2005, 24, 2582-2589.

Zhao, J.; Herdtweck, E.; Kühn, F. E., J. Organomet. Chem. 2006, 691, 2199-2206.

Collange, E.; Garcia, J.; Poli, R., New J. Chem. 2002, 26, 1249-1256.

Collange, E.; Metteau, L.; Richard, P.; Poli, R., Polyhedron 2004, 23, 2605-2610.

Hofmann, P., Angew. Chem., Int. Ed. Engl. 1977, 16, 536-537.

Schilling, B. E. R.; Hoffmann, R.; Lichtenberger, D. L., J. Am. Chem. Soc. 1979, 101, 585-591.

Schilling, B. E. R.; Hoffmann, R.; Faller, J. W., J. Am. Chem. Soc. 1979, 101, 592-598.

Johnson, T. J.; Folting, K.; Streib, W. E.; Martin, J. D.; Huffman, J. C.; Jackson, S. A.; Eisenstein, O.; Caulton, K. G., Inorg. Chem. 1995, 34, 488-499.

Ward, T. R.; Schafer, O.; Daul, C.; Hofmann, P., Organometallics 1997, 16, 3207-3215.

Smith, K. M.; Poli, R.; Legzdins, P., Chem. Commun. 1998, 1903-1904.

Smith, K. M.; Poli, R.; Legzdins, P., Chem. Eur. J. 1999, 5, 1598-1608.

Perrin, L.; Maron, L.; Eisenstein, O., Faraday Disc. 2003, 124, 25-39.

Han, Y.; Harlan, C. J.; Stoessel, P.; Frost, B. J.; Norton, J. R.; Miller, S.; Bridgewater, B.; Xu, Q., Inorg. Chem. 2001, 40, 2942-2952.

Kelly, C. P.; Cramer, C. J.; Truhlar, D. G., Journal of Physical Chemistry B 2006, 110, 1606616081.

Gun, J.; Modestov, A.; Lev, O.; Saurenz, D.; Vorotyntsev, M. A.; Poli, R., Eur. J. Inorg. Chem. 2003, 482-492.

Gun, J.; Modestov, A.; Lev, O.; Poli, R., Eur. J. Inorg. Chem. 2003, 2264-2272.

Wooster, N., Nature (London, United Kingdom) 1931, 127, 93.

Krebs, B., Acta Crystallogr., Sect. C: Struct. Crystallogr. Cryst. Chem. 1972, 28, 2222-31.

Lledós, A.; Bertrán, J., Tetrahedron Lett. 1981, 22, 775-8.

Ventura, O. N.; Lledos, A.; Bonaccorsi, R.; Bertran, J.; Tomasi, J., Theor. Chim. Acta 1987, 72, 175-95.

Lima, M. C. P.; Coutinho, K.; Canuto, S.; Rocha, W. R., J. Phys. Chem. A 2006, 110, 7253-7261.

Bergquist, C.; Bridgewater, B. M.; Harlan, C. J.; Norton, J. R.; Friesner, R. A.; Parkin, G., J. Am.

Chem. Soc. 2000, 122, 10581-10590.

Prabhakar, R.; Blomberg, M. R. A.; Siegbahn, P. E. M., Theoretical Chemistry Accounts 2000, 104, 461-470.

Sambrano, J. R.; Andres, J.; Gracia, L.; Safont, V. S.; Beltran, A., Chem. Phys. Lett. 2004, 384, 5662.

Hratchian, H. P.; Sonnenberg, J. L.; Hay, P. J.; Martin, R. L.; Bursten, B. E.; Schlegel, H. B., J. Phys. Chem. A 2005, 109, 8579-8586.

Erikson, T. K. G.; Mayer, J. M., Angew. Chem., Int. Ed. Engl. 1988, 27, 1527-1529.

Dovletoglou, A.; Meyer, T. J., J. Am. Chem. Soc. 1994, 116, 215-23. 
Comas-Vives, A.; Gonzalez-Arellano, C.; Corma, A.; Iglesias, M.; Sanchez, F.; Ujaque, G., J. Am. Chem. Soc. 2006, 128, 4756-4765.

Tunon, I.; Silla, E.; Bertran, J., J. Phys. Chem. 1993, 97, 5547-52.

Wei, D.; Salahub, D. R., J. Chem. Phys. 1994, 101, 7633-42.

Marx, D.; Tuckerman, M. E.; Hutter, J.; Parrinello, M., Nature (London) 1999, 397, 601-604.

Schmitt, U. W.; Voth, G. A., J. Chem. Phys. 1999, 111, 9361-9381.

Kovács, G.; Ujaque, G.; Lledós, A.; Joó, F., Organometallics 2006, 25, 862-872.

Kovács, G.; Schubert, G.; Joó, F.; Papai, I., Organometallics 2005, 24, 3059-3065.

Van Eldik, R.; Gaede, W.; Wieland, S.; Kraft, J.; Spitzer, M.; Palmer, D. A., Review of Scientific Instruments 1993, 64, 1355-7.

Frisch, M. J., et al., Gaussian 03, Revision C.02. ed.; Gaussian, Inc.: Wallingford CT, 2004.

Becke, A. D., J. Chem. Phys. 1993, 98, 5648-5652.

Lee, C. T.; Yang, W. T.; Parr, R. G., Phys. Rev. B 1988, 37, 785-789.

Stephens, P.; Devlin, F.; Chabalowski, C.; Frisch, M., J. Phys. Chem. 1994, 98, 11623-11627.

Hay, P. J.; Wadt, W. R., J. Chem. Phys. 1985, 82, 270-283.

Ehlers, A. W., et al., Chem. Phys. Lett. 1993, 208, 111-14.

Fukui, K., Acc. Chem. Res. 1981, 14, 363-8.

Gonzalez, C.; Schlegel, H. B., J. Chem. Phys. 1989, 90, 2154-61.

Gonzalez, C.; Schlegel, H. B., J. Phys. Chem. 1990, 94, 5523-7.

Barone, V.; Cossi, M., J. Phys. Chem. A 1998, 102, 1995-2001.

Cossi, M.; Rega, N.; Scalmani, G.; Barone, V., J. Comput. Chem. 2003, 24, 669-681. 


\section{Synopsis}

Combined protonation kinetics and DFT studies bring to light the regulating factors for the relative energy of dihydroxo vs. oxo aqua isomers, the water dissociation equilibrium, and abnormal acid dissociation constants, for the organometallic " $\mathrm{Cp} * \mathrm{MoO}_{2}(\mathrm{OH})+\mathrm{H}^{+}$” system.

\section{Table of Contents graphics}
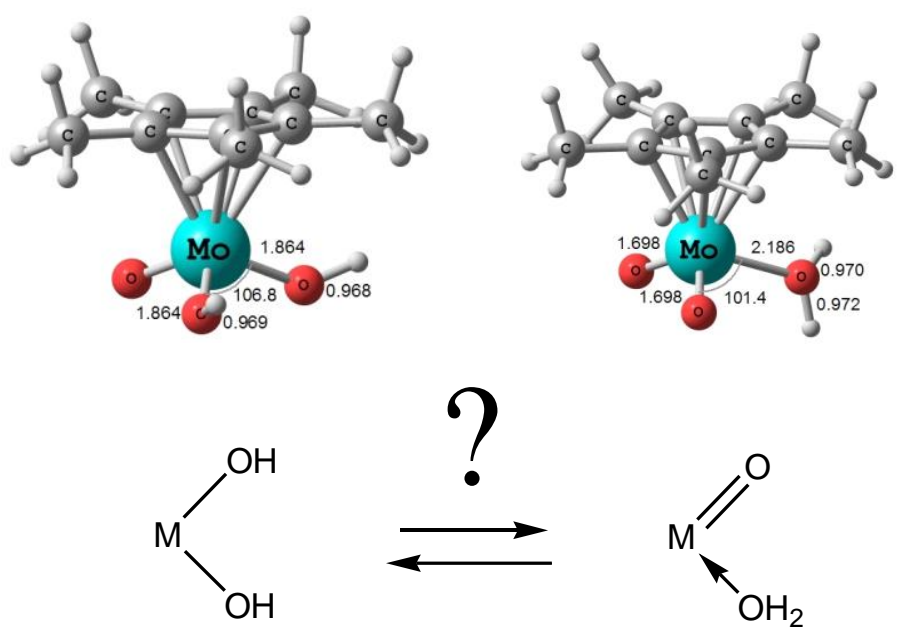